\title{
The Past and Future Ocean Circulation From a Contemporary Perspective
}

\author{
Carl Wunsch \\ Massachusetts Institute of Technology, Cambridge, Massachusetts, USA
}

Meridional overturning of the ocean, particularly the North Atlantic, is commonly invoked as the "trigger" and major cause of global climate change in a series of stories based upon a very simplified view of the circulation (a "conveyor belt"). Observational and computational progress in physical oceanography, however, over the last 30 years has rendered obsolete the old idea that the fluid ocean is a slowly changing, passive, almost geological system. Instead, it is a dynamically active, essentially turbulent fluid, in which large-scale tracer patterns arise from active turbulence and do not necessarily imply domination of the physics and climate system by large-scale flow fields. To the contrary, oceanic kinetic energy is dominated by the time- and space-varying components. The complexity of the resulting fluid pathways is an essential part of any zero-order description of the system. Thus general circulation models are the essential tool for understanding past, present and future climate states. Quantification of the likely major errors in using oversimplified models with inadequate turbulence closures and undersampled data becomes the main issue. Determining the past and future circulations is not easy, but hiding the difficulties is not a viable option.

\section{INTRODUCTION}

Physical, chemical, and circulation properties of the ocean are important elements of modern climate and its variability. Thus it is no surprise that these same properties are of intense interest to anyone attempting to understand the climate of the past or of the future. Meridional overturning rates, in particular, have been the focus of much of the discussion although it is important not to overemphasize a single, somewhat arbitrary, component of oceanic transport mechanisms. A reader of the literatures on past and future ocean circulations, and of that concerning the contemporary ocean, could, however, infer that the sciences are discordant and not obviously converging.

Much about the modern system remains inadequately described and understood, but a great deal is known, and in

Ocean Circulation: Mechanisms and Impacts

Geophysical Monograph Series 173

Copyright 2007 by the American Geophysical Union

10.1029/173GM06 particular, perception of the very nature of the ocean circulation has changed from the classical view. Unfortunately, this new understanding is sufficiently recent that little of it has penetrated the textbook literature or more generally into discussions of past and future climates. A central purpose of this Chapter, therefore, is to briefly sketch why much of the interpretation of past (particularly) and future ocean circulation states is viewed with skepticism bordering on disbelief in a large part of the oceanographic community.

As with the more general problem of climate, determining the meridional overturning circulation of the ocean can be divided conveniently into three major aspects, in approximate ascending order of difficulty: its characteristics (1) today; (2) in the past; (3) in the future. Acknowledging that the ocean circulation is a problem in fluid dynamics, the history of that subject shows that the combination of theory with observations (experiments) is essential. Without observations, theories rapidly become irrelevant or go badly awry; without theory, observations are uninterpretable. Thus for the contemporary ocean, we have substantial, if still incomplete, observations. For the ocean of the past, there are fragmentary 
data, and for the ocean of the future we have, by definition, no data at all. To keep the structure of this paper simple, I will focus primarily on (1) and (2), acknowledging that (3) is very important. Forecast problems are much like the paleoceanographic ones, albeit more difficult. (This ordering is oversimplified, and modeling e.g., millennial oscillations of the Cretaceous, may well be more elusive than forecasting global precipitation 100 years in the future. A major part of the relative difficulty would again be determined by data densities relative to the number and temporal/spatial structure of uncertain parameters.)

Much of the published focus on the role of the North Atlantic Ocean circulation invokes the meridional overturning circulation there in some way. Its rates, properties, and property transports are used to explain all kinds of phenomena. For example, the widely repeated explanation of the Younger Dryas episode is that cooling of the northern hemisphere (at least) was generated by the injection of massive amounts of freshwater from glacial melt, which overran the North Atlantic and weakened the "thermohaline circulation." (The latter is commonly not defined and the terminology is now almost useless. For example, the Bulletin of the American Meteorological Society, June 2006, p. 803, tells us that ". . . the thermohaline circulation, as measured in the Florida Straits, was near the long-term mean." One is left to guess that the reference is probably to the volume transport, which the author could have stated, but if there is any information being conveyed about the heat or salt transports [which are by definition "thermohaline," and require closed mass balances] the reader is left in the dark.) The Younger Dryas story raises several questions: (1) Whether there was a glacial melt episode at the right time (doubtful; see e.g., Bard et al., 1996, their Figure 4); (2) Whether the oceanic meridional mass flux decreased; (3) Whether the change in the ocean circulation was such as to cool the atmosphere over the whole northern hemisphere; (4) Whether the resulting change in the atmosphere had little or no a feedback on the inferred changed ocean circulation; (5) How was global heat balance maintained?

To understand some of the difficulties in connecting modern conceptions of the ocean circulation with this story, consider the issues facing a contemporary oceanographer attempting to understand the consequences of a large fresh water injection into the modern North Atlantic Ocean, perhaps through the St. Lawrence Valley. We suppose further that this oceanographer is using a numerical model of the North Atlantic Ocean. In attempting to understand the consequences of the hypothesis one would need to ask: (1) Does the fresh water immediately overrun the entire subpolar gyre? or, (2) Is it perhaps largely confined for some long period to the continental margin region in a boundary current - as rotation might dictate? (3) What does the injection of fresh water do to the local mixed-layer properties, and how rapidly is the water mixed laterally and vertically in the upper $100 \mathrm{~m}$ ? (4) How rapidly does the fluid enter the interior from the mixed layer and where? (5) How long does it take the fresh water anomaly to enter the regions of convection, and what is the effect of the anomaly on the convection? (6) Does convection slow, shift laterally, or penetrate to different depths? (7) What is the effect of the changed convection on the mass and salinity balances and how do they evolve in time? (8) Is the change in mass flux accompanied in some simple way by a change in the oceanic meridional heat transport? If so, what is its sign? (9) What happens to the sea ice distribution and how does that affect the ocean circulation and heat and salt budgets? (10) What happens to the atmospheric circulation during this series of events? How does the hemispheric temperature change and are there important feedbacks on the ocean or ice distribution? (11) Given that the ocean and atmospheric circulations including storm tracks are shifting, how are the global heat, freshwater, and angular momentum balances maintained? (12) What is the effect of these shifts on the (today) Greenland ice cap and is more or less fresh water thus injected? (13) Etc.

Physical representation and modelling issues exist concerning each of the elements of the list above, and as will be discussed below, little is known about model skill as a function of integration time. Errors in any one element could come to dominate any attempt at a forecast. For example, several recent papers (e.g., Huang, 1999; Nilsson et al., 2003; Wunsch, 2004) have shown that even a seemingly intuitive inference, that injection of fresh water into simple models necessarily slows the mass transport, is not obviously correct. General circulation model (GCM) response is also a delicate function of the specific boundary conditions used at the sea surface both for the dynamics (e.g., rigid lids or linearized kinematics) and for fresh water (e.g., Griffies, 2004), producing diverging solutions. Ignoring such issues, while relying upon primarily verbal argumentation-invoking what presumably are regarded as obvious scenarios or models of unknown accuracy-is one of the reasons for the skepticism already alluded to. Of course, not all of the literature accepts the "hosing-shutdown" scenario, but the story is surely the majority view and despite some mild cautionary words, is accepted in textbooks (e.g., Bradley, 1999, p. 271+) as having been demonstrated.

Many reasons exist to believe that the ocean circulation has a profound influence on climate; but whether the causes and consequences of those changes are well understood is doubtful. The message here is not one of hopelessness, but rather that the definition of a problem must be the first step in solving it, and that convenient assumptions should not be turned prematurely into "facts," nor uncertainties and ambiguities suppressed. Because climate change and the ocean circulation are important scientific problems that readily lend 
themselves to exciting and interesting just-so stories in the public media —including Hollywood — some restraint is called for.

\section{A BIT OF HISTORY}

Because of the need for observations in fluid mechanics, it is important to recognize that study of the contemporary ocean circulation tends to fall into two eras-prior to about 1992, and the period since then, when data became, relatively speaking, much more plentiful. Perception of the nature of the ocean circulation was largely a consequence of the available observational technology.

Historically, the fluid ocean has been extremely difficult and expensive to measure (some perspective can be found in Siedler et al, 2001; Wunsch, 2006a). Oceanographers from the start of the expeditionary era (dated to about 1870) found it necessary to combine observations obtained from global expeditions mounted over many decades - that is, treating the data as though they represented an unchanging system. Fortunately, descriptive oceanographers found that the gross distributions of measurable properties (mostly temperature and salinity, but sometimes oxygen and later, nutrients) were stably contourable over many decades and large areas, and the subject took on a geological flavor-being focussed on strata, water mass properties, and flows inferred to be broad-scale and sluggish.

Two other aspects of the science of the fluid ocean contributed importantly to the canonical picture that gradually emerged. The only globally measurable properties were temperature and salinity as functions of position, including depth. Following the development before 1900 of the socalled dynamic method, it was recognized that by calculating the density, $\rho$, of the fluid from an empirically determined equation of state, one could obtain the absolute flow in the ocean as a function of depth perpendicular to any two locations where $\rho(\phi, \lambda, z)$ was measured. $\phi, \lambda$ are latitude and longitude respectively, and $z$ is the radial (vertical) coordinate measured positive upward from the resting seasurface. So for example, the meridional velocity component, $v(\phi, \lambda, z, t)$, could be determined from the "thermal wind,"

$$
\begin{aligned}
& v(\phi, \lambda, z, t)= \\
& \frac{-g}{2 \Omega \sin \phi \rho(\phi, \lambda, z, t)} \int_{z_{0}}^{z} \frac{\partial \rho(\phi, \lambda, z, t)}{a \cos \phi \partial \lambda} d z+b(\phi, \lambda, t) \\
& -h(\phi, \lambda) \leq z, \quad z_{0} \leq 0, \quad \phi \neq 0 .
\end{aligned}
$$

See any introduction to physical oceanography (e.g., Sverdrup et al., 1942; Defant, 1961) for a derivation of this equation, in which $a$ is the Earth radius, $\Omega$ is the radian rate of rotation, $g$ is gravity and $z=-h(\phi, \lambda)$ is the sea floor. The equation is a result of the observed near-dynamical balance called "geostrophy." In practice, the derivative is computed by a simple horizontal difference, and the integral is computed as a sum, but the pretence of continuous data allows a tidier notation with no fundamental distortion. A similar equation relates the zonal velocity, $u$, to the $\phi$ derivative of $\rho$.

The attraction of Eq. (1) is that the volume flux, $v$ (or mass flux, $\rho v$ ), in the ocean could be computed from shipboard measurements of temperature and salinity alone, and this dynamic method became a routine tool. A difficulty was recognized - the integration constant, $b(\phi, \lambda)$, not depending upon $z$, in Eq. (1) was unknown. $b$ is the velocity at the socalled reference level, $z_{0}$. To use the dynamic method, all one requires is for the velocity to be known at any single depth, $z_{0}(\phi, \lambda)$, which is otherwise arbitrary.

Attempts to directly measure the flow from ships in the open sea (anywhere below, but not right at, the sea surface to avoid the most obvious effects of the local wind) all failed. It was found that the flow fields even at large depths varied greatly in direction and magnitude from minute to minute and out to the longest time scales that one could afford to keep a ship at one (nominal) fixed location in the open sea. This intense variability in the flow field was apparently at odds with the permanence of the structures in temperature and salinity themselves, and implicitly or otherwise, it came to be regarded as a kind of irrelevant "noise." If one could not therefore directly measure $b$, something else had to be done. As discussed in all textbooks (e.g., Sverdrup et al., 1942; Defant, 1961; Wunsch, 1996, Chapter 2) the plausible assumption was made that there existed some large depth, $z_{0} \ll 0$, where $v$ and hence $b$, vanished; that is, it was assumed that there was a "level-of-no-motion."

A level-of-no-motion permitted calculation of the absolute flow field, but it also seemed to imply that one could forego measurements below that depth-resulting in large savings in time, money, and equipment wear and tear. Implicitly, it was assumed that the ocean circulation was dominantly a consequence of the wind, with effects expected to be small at great depths, and therefore nearly vanishing below the level-of-nomotion. Textbooks should be consulted for discussion of how choices of level-of-no-motion were made, but most commonly they corresponded to isotherms, isopycnals, or fixed depths (e.g., $1000 \mathrm{~m}$ ), or by assuming them to lie between water masses believed to be moving in different directions (e.g., above the North Atlantic Deep Water and below the Circumpolar Intermediate Water).

Another useful characteristic of the physics leading to Eq. (1) is that the total amount of water moving normal to the station pair above $z_{0}$ was independent of the distance between the pair (because of the $\lambda$ derivative), if bottom topography did not intervene. Close pairs (separated, e.g., by $\Delta \lambda$ ) gave temporally much less stable horizontal derivatives e.g., $\partial \rho / \partial \lambda \approx \Delta \rho / \Delta \lambda$, than did widely separated ones and this 
experience also implied that only widely separated station positions are required.

Along with the contoured property fields (see e.g., Plates 1 or 2), a reasonably self-consistent picture of the ocean as a large-scale, essentially steady flow emerged, one in which the abyssal components were thought to be so weak as to be hardly worth discussing, and in which the upper ocean flows, believed known, varied significantly only on time scales of hundreds or thousands of years. That the results were only qualitative can be inferred from the variety of contradictory upper ocean circulation patterns that were published over the years; Reid (1981) conveniently displays some of them.

Buttressing this picture was the development, beginning in the late 1940s, of dynamical oceanography, in which it was finally recognized that the ocean circulation was a problem of fluid dynamics, and hence susceptible to mathematical representation and analysis. Beginning with Sverdrup (1947), Stommel (1948), Munk (1950) and the many papers that followed, an elegant theoretical framework was constructed using the same equations that lead to Eq. (1) and representing again, the assumed large-scale, nearly steady oceanic circulation-observations driving the theory (see e.g., Pedlosky, 1996, and references there.)

Today this canonical picture of the ocean circulation pervades the literature - as an essentially steady, laminar, largescale flow. Cutting a long story short, it is one that culminated in its depiction as a very simple one-dimensional ribbon "global-conveyor," and now appears in all textbooks down to the high school level as well as in professional monographs and at least two Hollywood movies. It clearly underlies the thinking about phenomena such as the Younger Dryas alluded to in the Introduction. Unfortunately, it appears to be wrong, not only in its basic pathways (for a brief summary, see Wunsch, 2002), but more important, in its rendering of a grossly oversimplified idealization. The latter produces the powerful implication that the ocean circulation is so uninteresting that anyone, scientist or not, can deduce how it has changed in the past, and how it will necessarily change in the future! But the canonical picture began to unravel 30 years ago.

\section{THE THERMAL WIND, LEVELS-OF-NO-MOTION, PROPERTY TRANSPORTS}

The use of levels-of-no-motion had troubled physical oceanographers for many years (e.g., Sverdrup et al., 1942; Defant, 1961). It was only in the 1970 s that so-called inverse methods (including such forms as the $\beta$-spiral) removed the necessity of the assumption (for a summary see Chapter 2 of Wunsch, 1996). It quickly became obvious that oceanic flows satisfying Eq. (1) looked little like the layered, quasi-steady movements that had been inferred from the watermass prop- erties. Rather they were columnar in nature (see Figure 1), with zero flow lines oriented much more nearly vertically than horizontally. It was this feature of the earliest solutions from inverse methods, contradicting the canonical picture, that led many physical oceanographers to simply reject the methods as erroneous - an example of how a working assumption - that there exist levels-of-no-motion-became translated into a fact. Subsequently, direct observations with the new time-series technologies supported the inference that geostrophically balanced oceanic flows do not coincide with water masses.

An argument against the importance of the intricate structures seen in such diagrams as Figure 1 is that they are equivalent to the supposedly irrelevant "noise" used to explain away the extremely variable current meter records; one could argue that a time-average would indeed reproduce the layered quasi-geological structures of the canonical view. Unhappily, there is no evidence that averaging does produce such simple structures. Three examples are shown in Figure 2 and Plates 3 and 4 - one from modern direct current meter measurements over two years [Whitworth et al., 1999], one from the 12-year average of a numerical model, and the third from almost three years of float data [Hogg and Owens, 1999]. At the moment, the burden of proof would appear to be on anyone who sought to claim that both (1) layered flows would emerge given sufficiently long-averaging times and (2) property fluxes carried by the time varying flows are negligible compared to those from the time averages. Neither has yet been demonstrated for the open ocean. Intense mean flows such as the Gulf Stream or Antarctic Circumpolar Current may be exceptional, relative to point 2, in that regard, but are hardly typical; see Joyce et al. (2001), for another example.

There is no good available rendering of the structure of the global horizontal flow field - it is too complicated and timedependent (cf. Macdonald and Wunsch, 1996) - but Plate 5 perhaps gives some of its flavor. As taken from Fratantoni (2001), it shows surface drifter trajectories over several years in the North Atlantic. Spatial coverage is incomplete and there are a number of corrections made to render float displacement as water parcel movement, but there is little doubt that any depiction of actual water movement as a large-scale simple steady flow field is not likely to be even qualitatively correct. Water parcel pathways are torturous and always time-evolving and these features of the flow are basic to its consequences.

Mass flux is central to the discussion of oceanic dynamics, and it controls much of the climate system, but the interactions with the rest of the system (the atmosphere and cryosphere) depend on the mass flux only through property exchanges with the ocean. That is, the atmosphere only knows or "cares" about oceanic seasurface temperatures, and it is irrelevant to the atmosphere whether those temperatures 


\section{Nitrate $(\mu \mathrm{mol} / \mathrm{kg}) 27.3 \gamma^{\mathrm{n}}\left(\mathrm{kg} / \mathrm{m}^{3}\right)$}

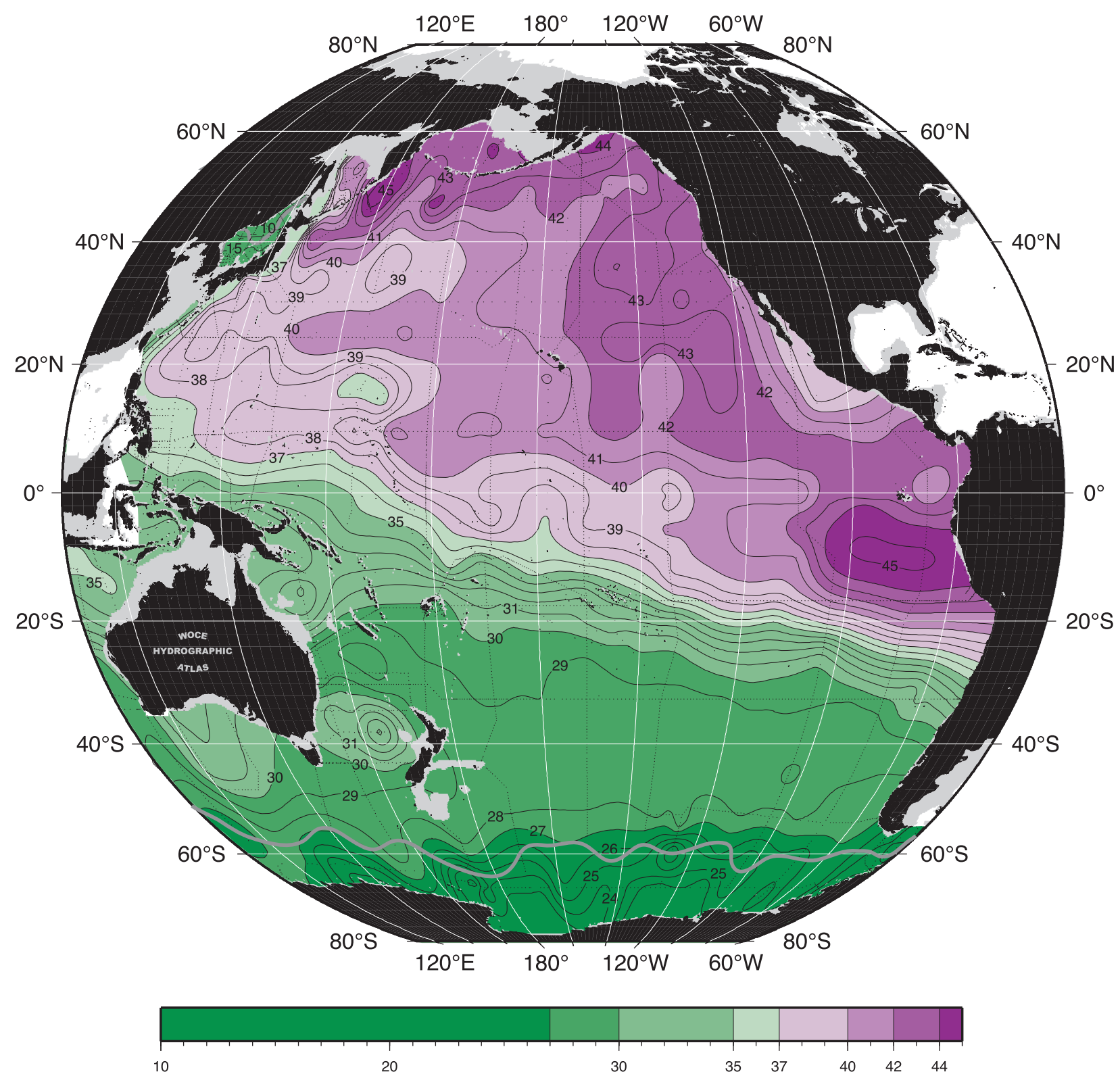

Plate 1. From the Pacific WOCE Atlas (Talley, 2007) showing contoured nitrate on a surface of constant density ( $\approx 800 \mathrm{~m}$ depth). Historically, these patterns were interpreted to imply that the flow field occurred on the same large spatial scale. Unfortunately, the conclusion is a non-sequitur and appears incorrect over much of the ocean. 


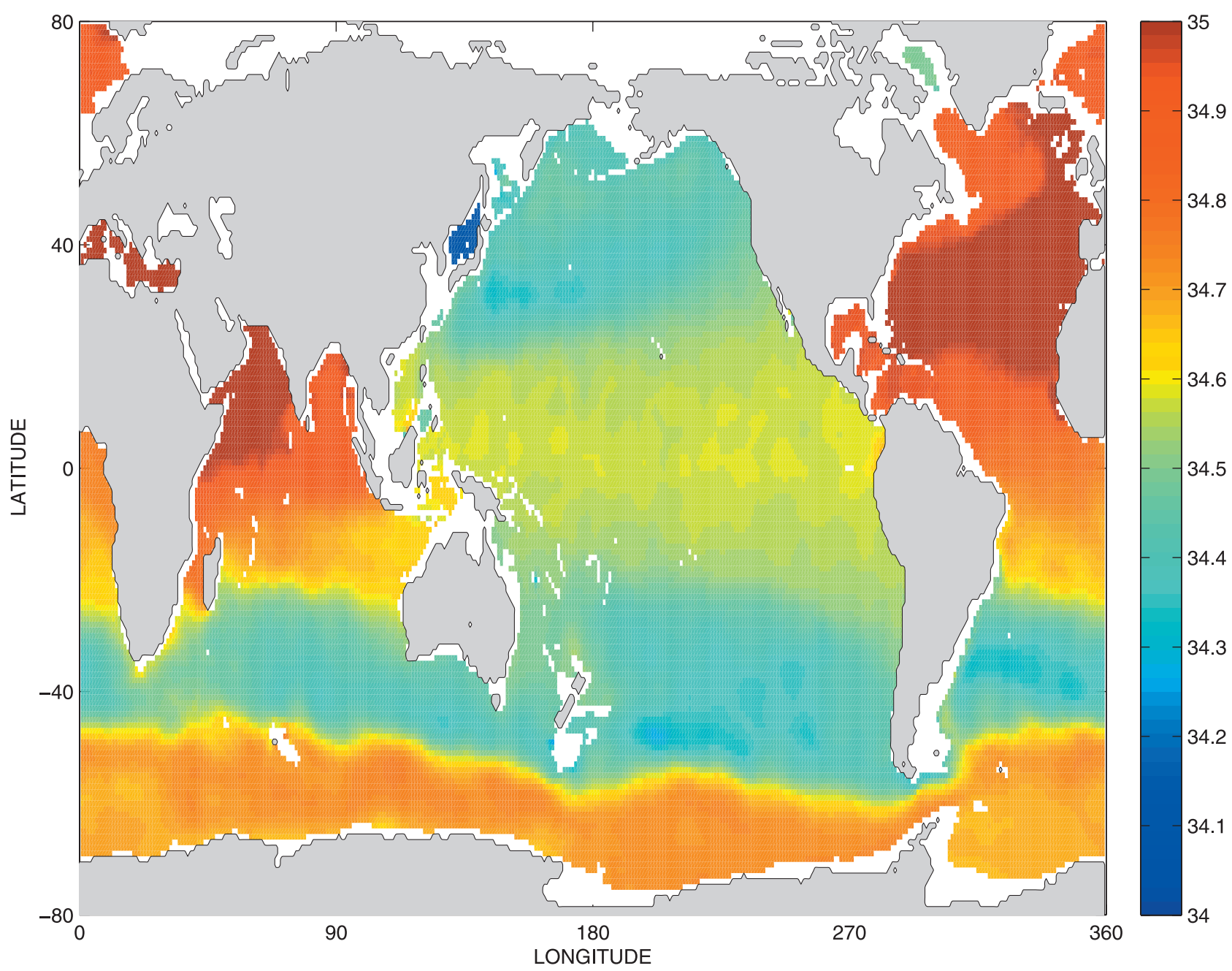

Plate 2. Salinity at $1165 \mathrm{~m}$ from a global state estimation (see Wunsch and Heimbach, 2006). Like the nitrate field in Plate 1, the salinity has a much larger scale structure than does any obvious flow pattern governing it.

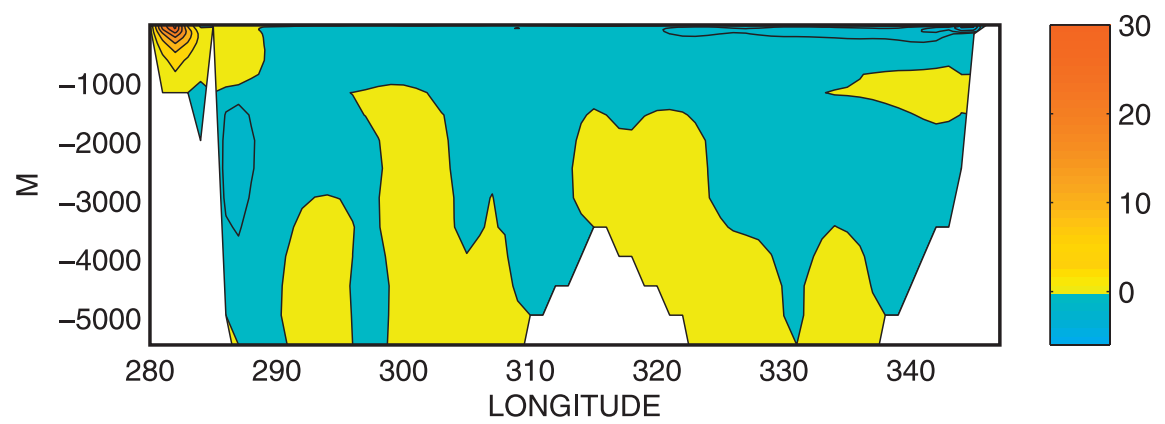

Plate 3. 12-year mean velocity $(\mathrm{cm} / \mathrm{s})$ at $26^{\circ} \mathrm{N}$ in the North Atlantic from a data-constrained model. Blue areas are flowing southwards. Note that the flow boundaries do not have a simple connection with the water mass structure, even after 12 years of averaging. An Antilles Current and a weak deep western boundary current are visible. (From Wunsch and Heimbach, 2006.) Corresponding temperature and variability fields are described in the paper. 


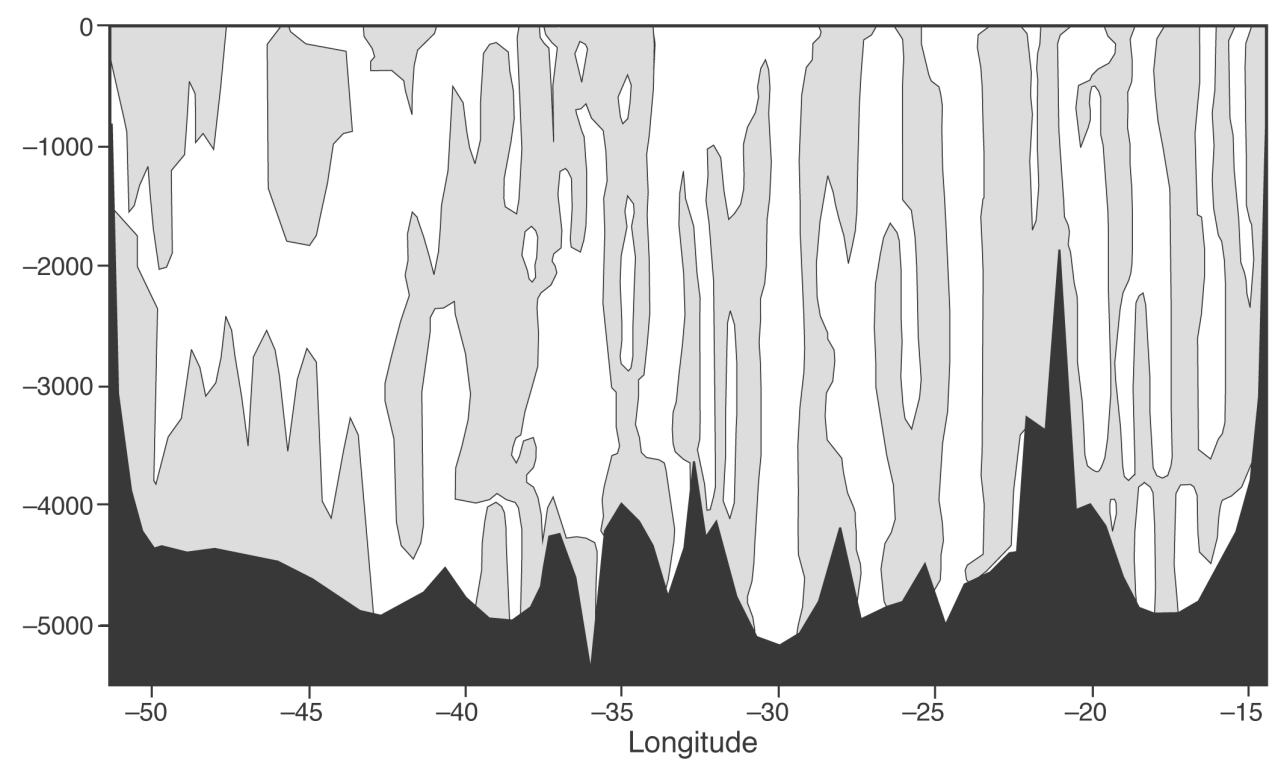

Figure 1. Absolute geostrophic velocity estimate at $7.5^{\circ} \mathrm{N}$ in a section across the North Atlantic Ocean (see Ganachaud, 1999, for a fully contoured version). Velocities range over approximately $\pm 50 \mathrm{~cm} / \mathrm{s}$. Clear areas depict northward flows, stippled southward ones. To determine the flux of a particular property demands multiplying this field by the concentration distribution, and integrating zonally and vertically. An Ekman component in the upper approximately $100 \mathrm{~m}$ is not shown here. Calculations such as this come as close as is possible using hydrography alone to producing a "snapshot" of the flow. Figure 2 and Plate 3 are averages and suggest that most of the structure is persistent.

are maintained primarily by the meridional overturning or gyre circulations or by specific mixed layer physics. The climate system is determined in part by how much, and where, the ocean is carrying heat, freshwater, carbon, etc., and where and at what rates they are exchanged with the atmosphere. Of primary importance are the vertical and horizontal transports of properties, which in the horizontal depend upon products such as $\rho(\phi, \lambda, z, t) \mathbf{v}(\phi, \lambda, z, t) C(\phi, \lambda, z, t)$. Calculating the transport of any property, $C(\phi, \lambda, z, t)$, across the zonal line shown in Figure 1 involves the integration,

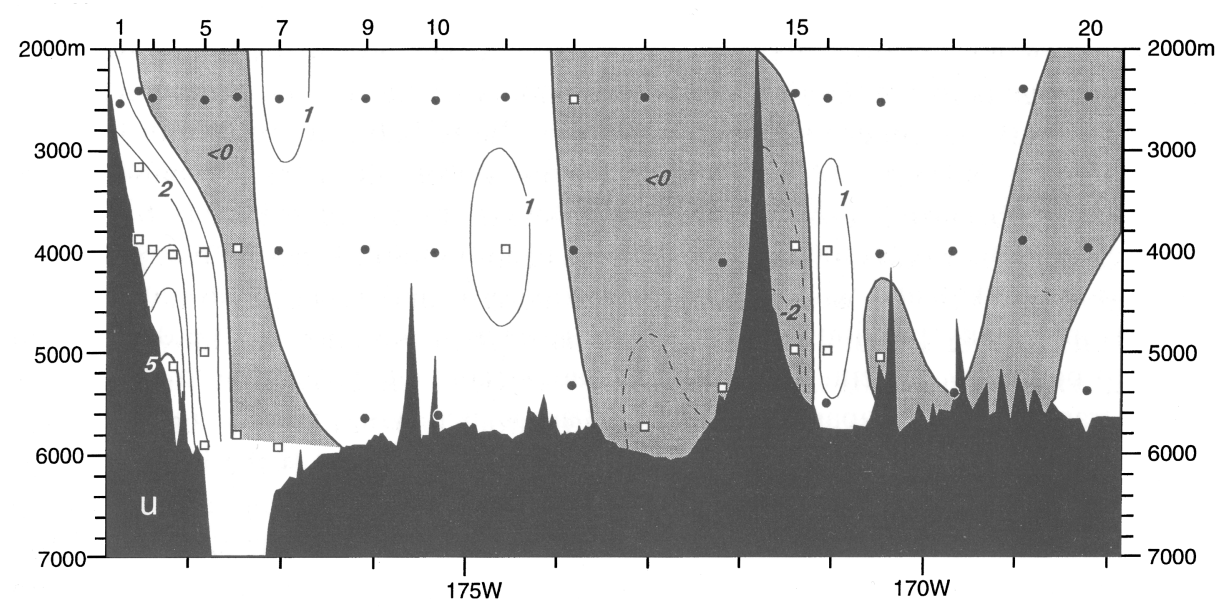

Figure 2. Cellular nature of the mean meridional flow $(\mathrm{cm} / \mathrm{s})$ from direct current meter measurements over two years (Whitworth et al., 1999). Data are from an array extending into the South Pacific Ocean at about $32^{\circ} 30^{\prime} \mathrm{S}$. Note that only the region below $2000 \mathrm{~m}$ is depicted. 


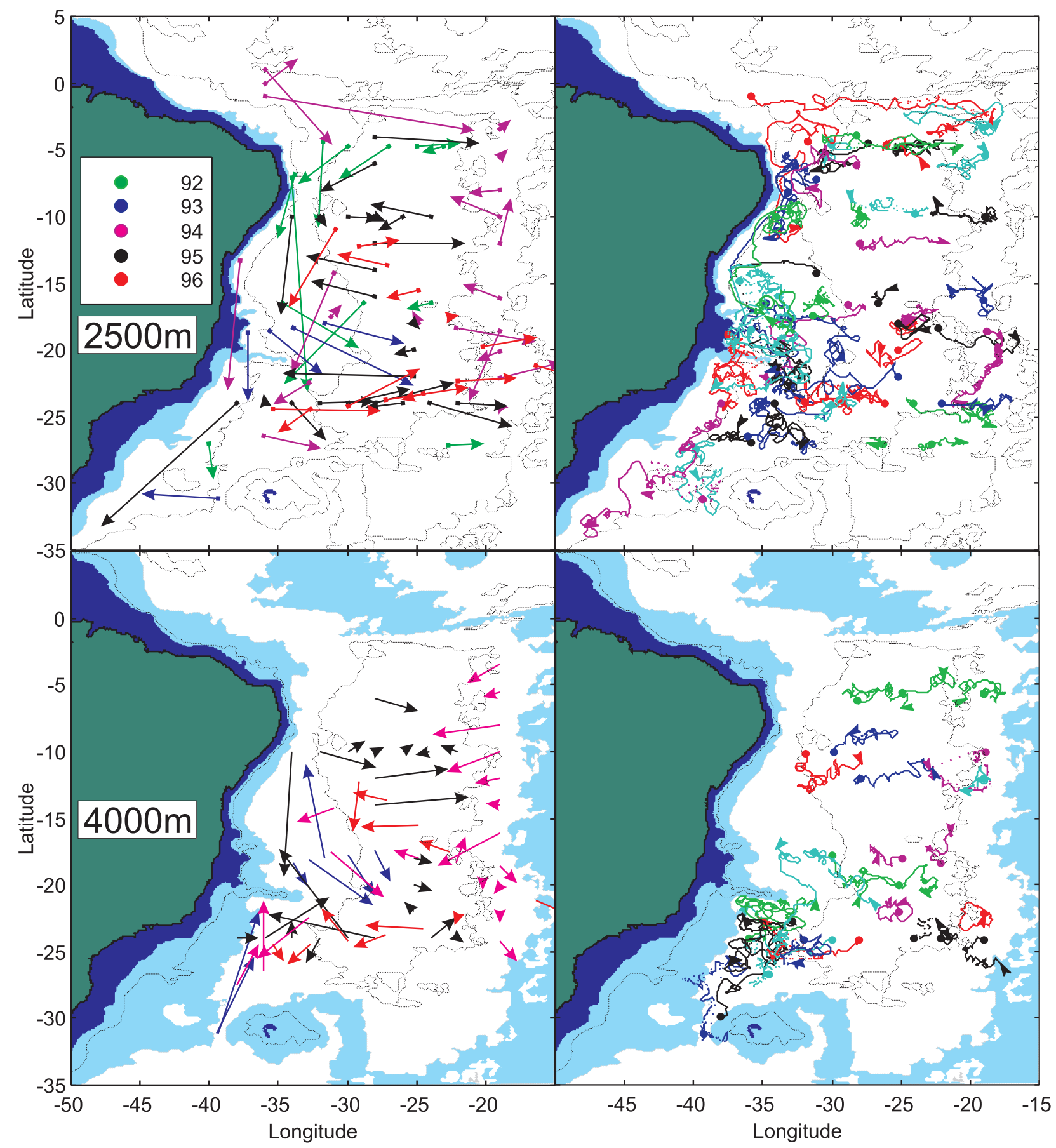

Plate 4. Displacements of neutrally buoyant floats (left panels) at two depths in the Brazil Basin Experiment (N. Hogg, private communication, 2007; see Hogg and Owens, 1999). Colors correspond to year of observation, and all durations are between 600 and 800 days. Right panels show trajectories as determined every 2 days. This region is one of large-scale property tongues oriented north-south, and one should note both the strong tendency to zonality and the short meridional scale of fluctuation. Current meter records are consistent, too, in showing a great deal of temporal and spatial variability. Very close to the coastline there may be a statistically significant net southward flow. 

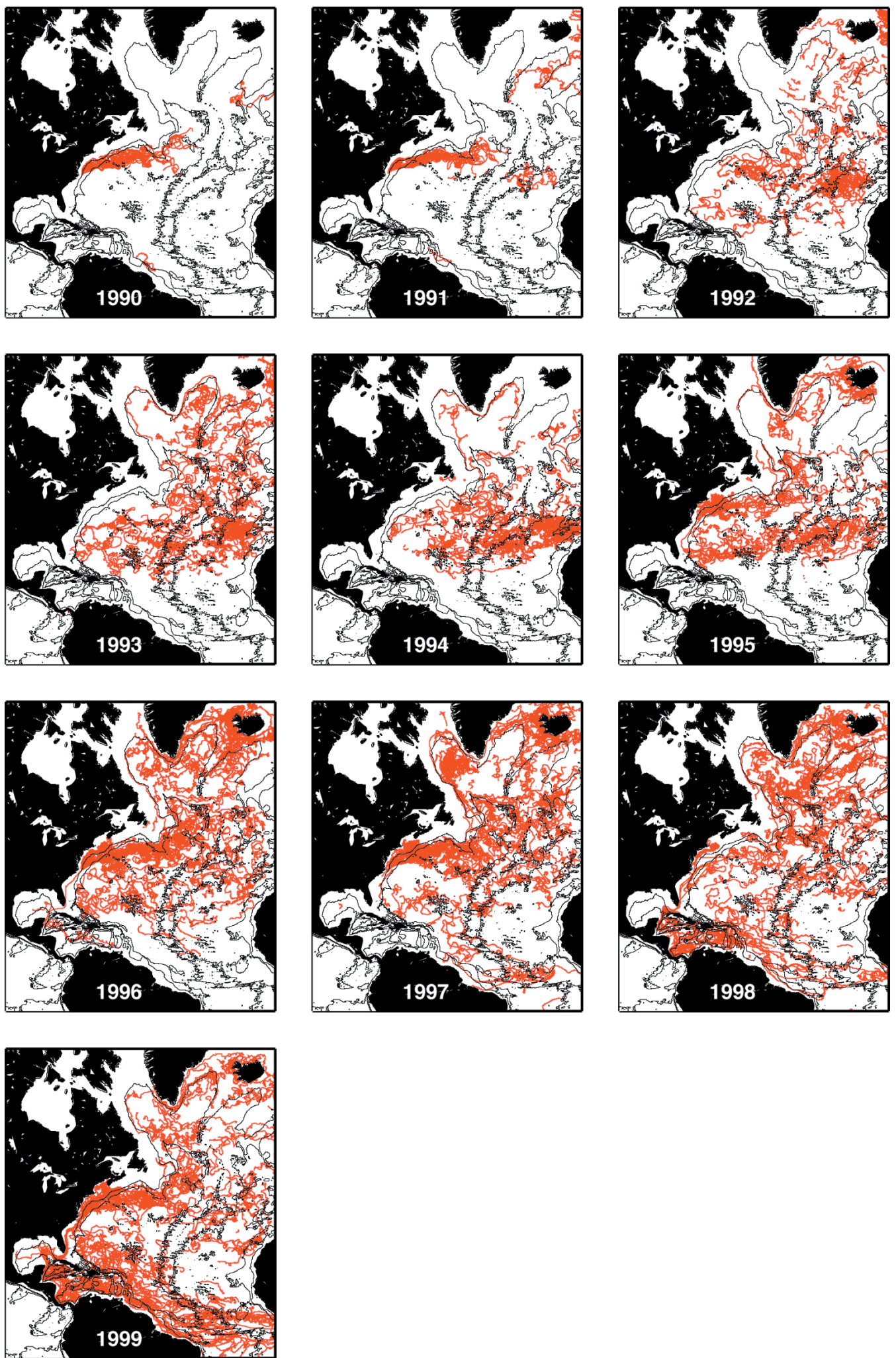

Plate 5. Trajectories (from Fratantoni, 2001) of surface drifters in the North Atlantic for different years. Although difficult to characterize, one obtains a sense of the complexity of water pathways near the surface and the difficulty of inferring that large-scale putative streamlines describe the actual flow. 


$$
\begin{aligned}
H_{C}(\phi, t)= & \int_{0}^{L} \int_{z=-h(\phi, \lambda)}^{0} \rho(\phi, \lambda, z, t) v(\phi, \lambda, z, t) \\
& C(\phi, \lambda, z, t) a \cos \phi d z d \lambda
\end{aligned}
$$

assuming for simplicity that $\phi$ is a fixed latitude. That is, oceanic transport properties involve the products of velocities or mass transports and property distributions (that is, the second-order moments or covariances). One can try to replace the computation of $H_{C}$ by the product of the first moments - the average mass transports and values of $C$ (assumed somehow known),

$$
H_{C}(\phi, t) \approx L \bar{h} \bar{\rho} \bar{\nu} \bar{C}
$$

where the bars indicate the vertical and horizontal averages, or by variants, for example, involving zonal averages summed in the vertical. Do the results from Eq. (3) have any quantitative resemblance to those in Eq. (2), for flows such as in Figure 1? It is very improbable. Even sign reversals have been encountered in moving from one form to the other; see Brewer et al. (1989) and Martel and Wunsch (1993) for the case of carbon transport. In the modern ocean, use of Eq. (2) would be regarded as essential (see Ganachaud, 1999; Ganachaud and Wunsch, 2002). Computation of useful second moments in turbulent fluids is not so easy, particularly if the first moments are inaccurate.

Wunsch and Heimbach (2006) used their near-optimized model to calculate the mass and heat transports across $26^{\circ} \mathrm{N}$ in the North Atlantic as a function of time. The result is instructive. Figure 3 displays the month-by-month variability in mass and temperature transports in three oceanic depth ranges. Month-to-month variability occurs in both mass and temperature with the mid-depth range showing almost $100 \%$ variability over 12 years: the ocean is noisy. Mass and temperature transports are clearly correlated in the upper ocean, but the weak trend in the mass transport does not appear in the temperature transport. Such results do not disprove the possibility of computing oceanic meridional heat transports
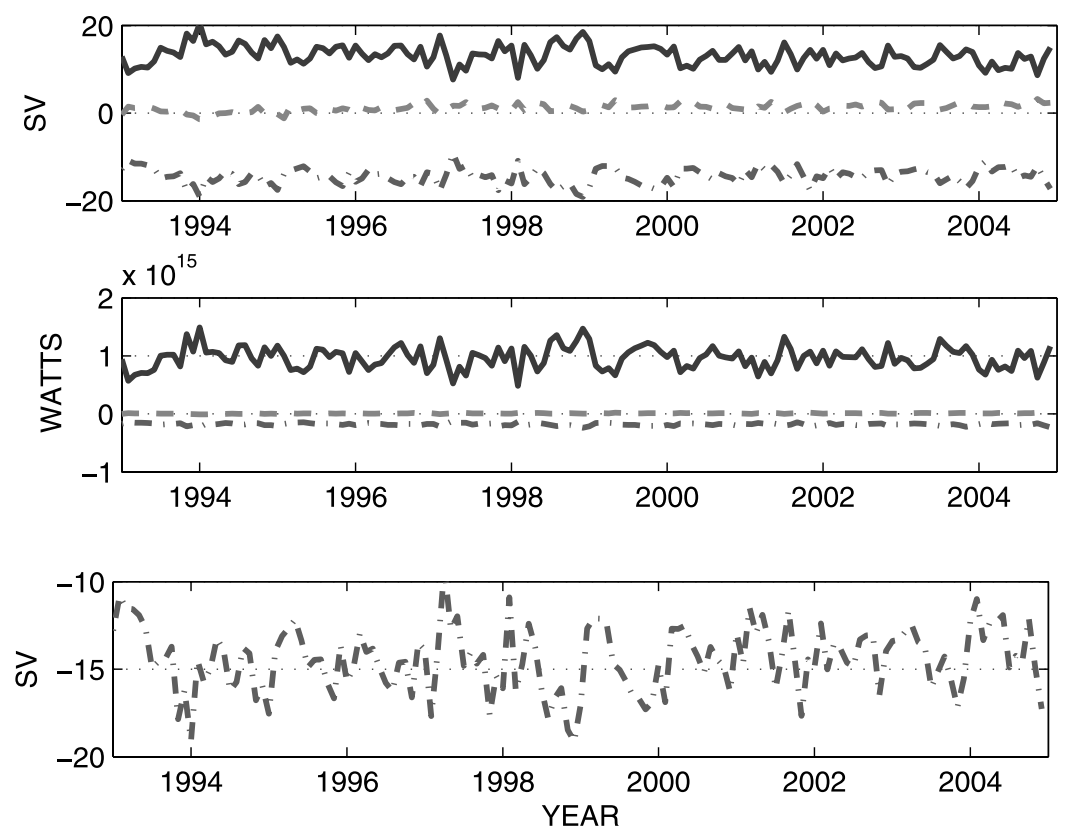

Figure 3. (Upper panel) Monthly mean zonal and vertically integrated volume flux above $1165 \mathrm{~m}$ (solid line), between 1165 and $4450 \mathrm{~m}$ (dash-dot), and $4450 \mathrm{~m}$ to the bottom (dashed line). (Middle panel) Vertically integrated temperature flux (based on $0^{\circ} \mathrm{C}$ ) from the surface to $1165 \mathrm{~m}(1165-4450 \mathrm{~m})$ and from $4450 \mathrm{~m}$ to the bottom. The weak decreasing trend in the volume flux of the upper ocean, and corresponding increases in the flux in the mid-depth and abyssal waters, are visible by eye. The month-to-month variability is large (the $1165 \mathrm{~m}$ to $4450 \mathrm{~m}$ volume flux varies between -9 and $-19 \mathrm{~Sv}$ ) leading to the high probability of aliasing in subsampled estimates. (Bottom panel) Expanded scale version of the 1165-4450m curve in the top panel to emphasize the month-to-month variability (from Wunsch and Heimbach, 2006). The large variability is dynamically and kinematically important in understanding how the ocean operates and how it might differ in the past and future. Variability arises from both external forcing (6-hourly wind and buoyancy exchange estimates are used) and internal processes. 
from subsampled or averaged fields, but claims to accuracy or precision must be quantified.

How large an error can be tolerated in the covariance calculation? Take the area of the North Atlantic Ocean poleward of $26^{\circ} \mathrm{N}$ to be very roughly $10^{13} \mathrm{~m}^{2}$. Then, using the first moments for scale, a flux change through the seasurface of $1 \mathrm{~W} / \mathrm{m}^{2}$ corresponds to $10^{13} \mathrm{~W}=0.01 \mathrm{PW}$ heat transport change across $26^{\circ} \mathrm{N}$. If the modern value (Figure 3 ) is taken to be $1 \mathrm{PW}$, a $1 \%$ error would encompass estimates of current oceanic warming rates under anthropogenic $\mathrm{CO}_{2}$ increase, with all of the climate changes that are anticipated from it. With a fluid heat capacity of $4 \times 10^{3} \mathrm{~J} / \mathrm{kg}$, and $15 \times 10^{9} \mathrm{~kg} / \mathrm{s}$ moving poleward above $1000 \mathrm{~m}$ and assumed returning below that depth with temperature difference of $\Delta T^{\circ} \mathrm{C}$, the heat energy transport is $\left(6 \times 10^{13} \Delta T\right) \mathrm{W}$. Thus an error in the average vertical temperature difference of $0.2^{\circ} \mathrm{C}$ exceeds the estimated present anthropogenic change. If the vertical temperature difference in northward- and southward-going flows is $17^{\circ} \mathrm{C}$, then a mean mass flux error of $0.1 \mathrm{~Sv}$ also produces an error near the anthropogenic signal. Given undersampling in space and time, can one directly compute property/transport covariances approaching this accuracy?

In the paleoceanographic problem, remarkably few profiles $C(\phi, \lambda, z, t)$ are sometimes used to draw inferences about transports across the entire ocean width, or in some cases $(Y u$ et al., 1996; McManus et al., 2004) vertical integrals of the water column as recorded in the sediments are employed, with the latter authors using a single sediment record. Whether such calculations are reliable, and even if reliable whether they are stable functions of the time, $t$, is doubtful. They should be regarded as assumptions used to speculate about possible consequences rather than as actual past oceanic transports. If carefully labelled as speculations, they can be useful in suggesting further tests or data.

\section{THE STEADINESS ASSUMPTION}

Another comparatively recent conceptual shift in physical oceanography came from the growing recognition that the oceanic flow field was dominated by comparatively smallscale features - of order $100 \mathrm{~km}$ across - called "mesoscale eddies" (a misnomer now impossible to eradicate, but we will refer to them here as "geostrophic eddies"). This tale has been told many times, and a useful early account is Robinson (1983). To summarize the situation, Plate 6 displays the oceanic kinetic energy for the mean, the time-variability, and their ratio in the geostrophic surface flow. The ratio is a complex function of position and the computation has known errors, but it is almost universally true that there is two orders of magnitude more energy in the variability than in the sevenyear time-mean. One can simply assume that the variability has no consequences for large-scale property transports or oceanic dynamics, but that assumption is an extreme one, equivalent to asserting that weather has no effect on climate.

But even the large-scales are very variable. Plate 7 shows the annual average sea level anomaly relative to a 14 -year combined model/data mean (see Wunsch and Heimbach, 2006). These structures result from both baroclinic and barotropic signals and they are not readily separated by eye. If the time variability is to be ignored, one must demonstrate that the temporal variations are neither significant contributors to property transports nor do they present sampling issues.

Geostrophic eddies introduce important non-linear terms into the equations of motion, whether it be for momentum in the form, $\mathbf{u} \cdot \nabla \mathbf{u}$, or in property transport equations such as $\mathbf{u} \cdot \nabla C$. The time scales of the eddies are order of tens to hundreds of days, and so theory is directed at time averages of these quantities, $\langle\mathbf{u} \cdot \nabla \mathbf{u}\rangle,\langle\mathbf{u} \cdot \nabla C\rangle$, where the brackets indicate an average over a time that is long compared to the eddy lifetime, but short compared to that of the larger scale flow (assuming that such a separation is possible). Much attention has been devoted by theoreticians to writing these non-linear terms in various forms (see McIntyre, 2000, or Vallis, 2006, for review), permitting more transparent interpretation or calculation or to represent them in terms of the slowly varying properties, $\langle\mathbf{u}\rangle,\langle C\rangle$, in what are turbulence closure assumptions. Over much of the ocean, the eddy flux terms do not appear very important, but in a number of crucial regions, near western boundary currents, and in particular over the entire Southern Ocean, they are critical, even dominant. Theories, simulations or predictions of the global circulation not accounting for eddy flux terms are likely to be erroneous, but the accuracy of present parameterization schemes is the subject of intense debate.

\section{MODEL PROBLEMS}

Numerical models, particularly those known as GCMs, are the central tool for understanding the ocean circulation in any epoch. Models are essential, because the equations of fluid dynamics and ancillary ones such as thermodynamics and biogeochemistry represent all theoretical knowledge but cannot be solved analytically. A good numerical model represents all of the elements believed necessary to replicate the physics of the circulation and preferably (but extremely rarely) with known accuracy. In addition, GCMs are the only way to synthesize the extremely diverse observation types into a consistent picture.

Modern ocean GCMs are very complex pieces of numerical machinery, embodying a great range of inferences, approximations, tuning parameters, and theory. These models are used to represent the ocean circulation over time scales 
a)

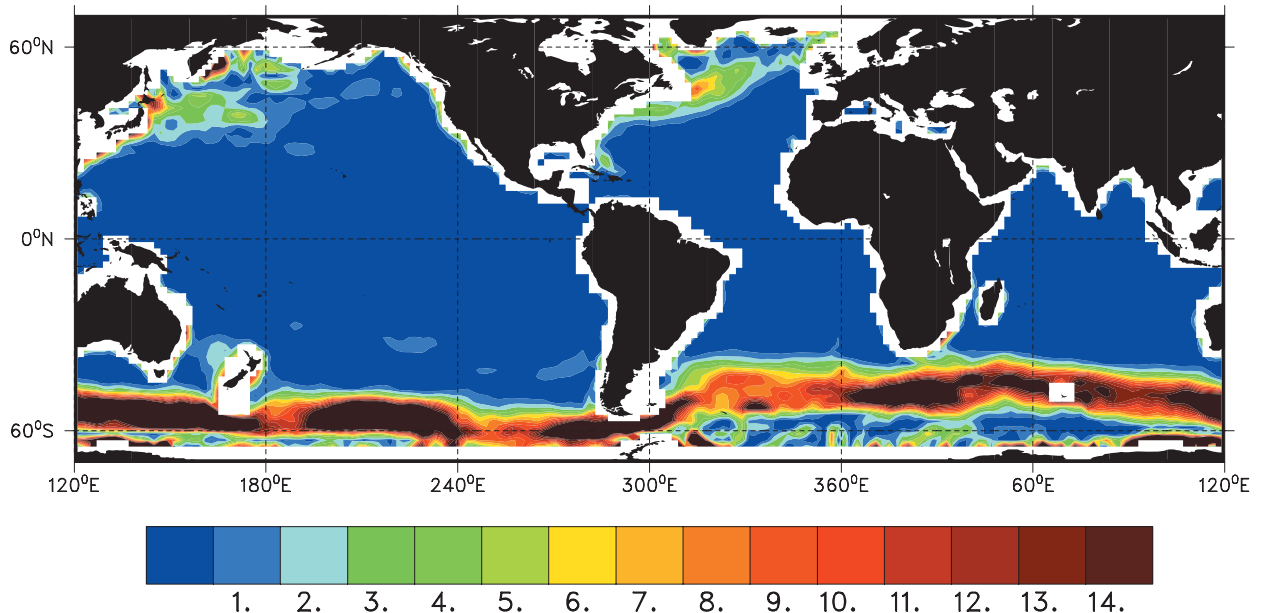

b)

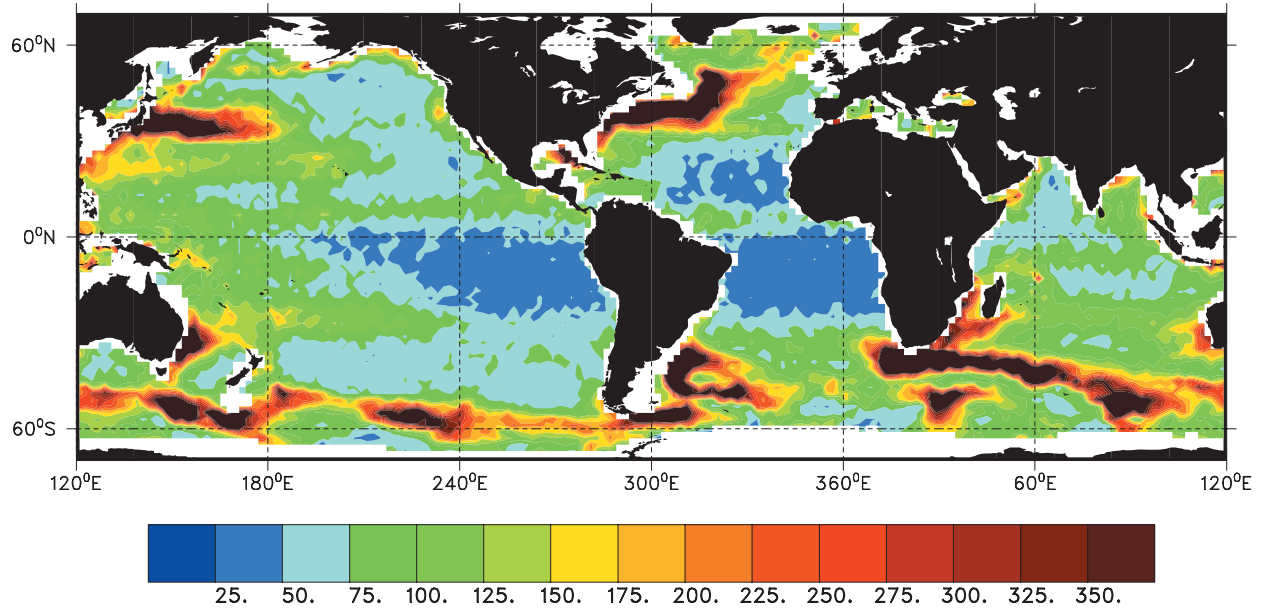

c)

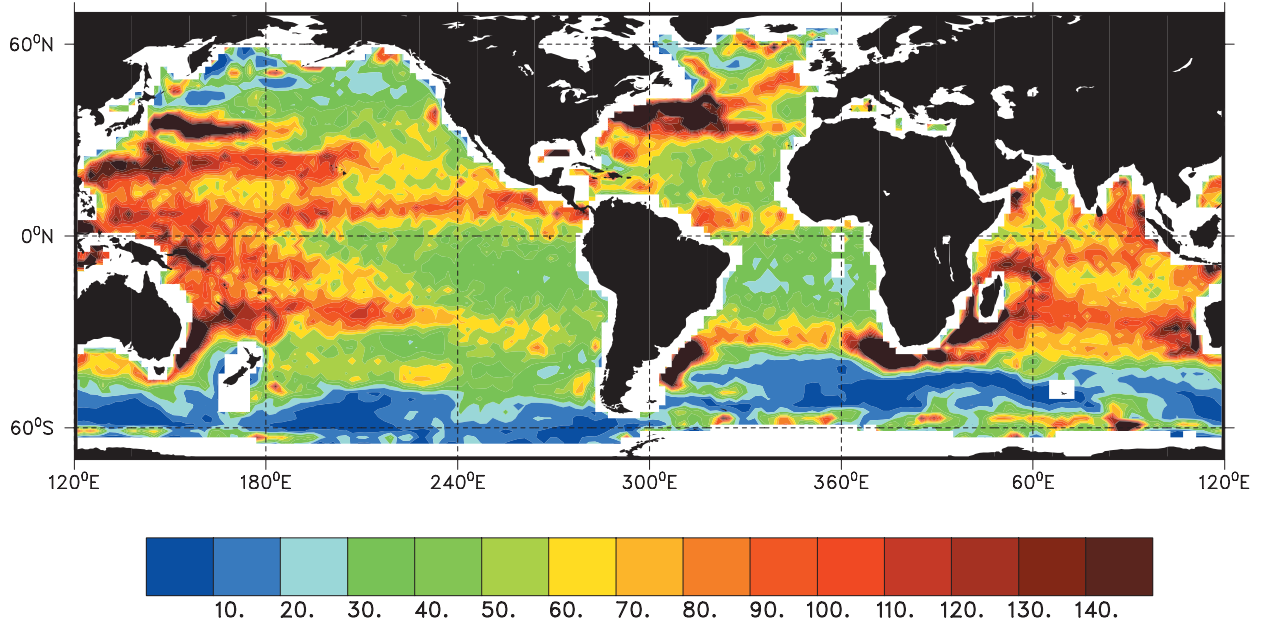

Plate 6. Kinetic energy (KE) of the mean geostrophic flow (upper panel), and of its time variability (middle panel) from seven years of altimetry, with their ratio in lowest panel. Both plots were multiplied by $\sin ^{2} \phi$, where $\phi$ is the latitude, so as to suppress the equatorial singularity of geostophic balance. The variability is generally 100 times larger than the mean as measured by their KE. KE of the mean is generally somewhat overestimated because the geoid employed is too smooth at short scales, leaving structures in the surface elevation that are present because of gravity field variations rather than the presence of oceanic flow. The ratio, on average, is thus a lower bound. Strong spatial variations in the ratio and its generally large amplitude put the burden of proof on modellers to show that the eddy flux effects do not introduce large systematic errors in long integrations. Source: Wunsch, 2002, corrected. 
1993

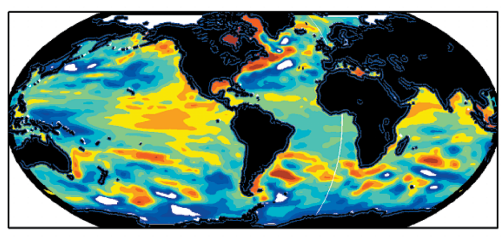

1997

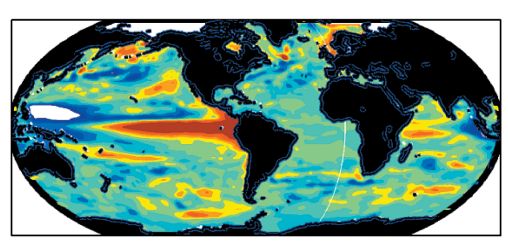

2001

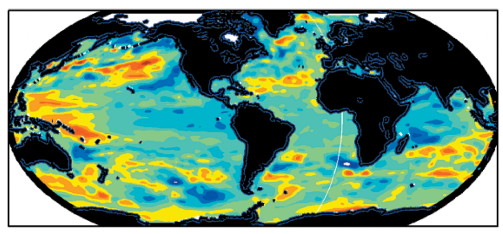

1995

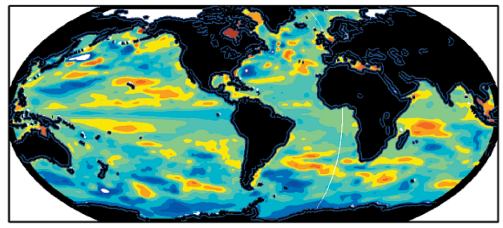

1999

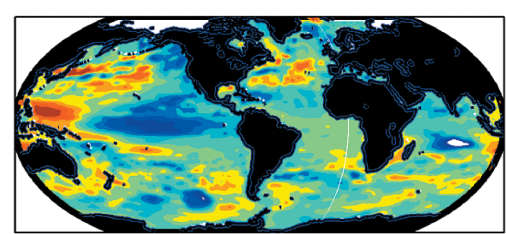

2003

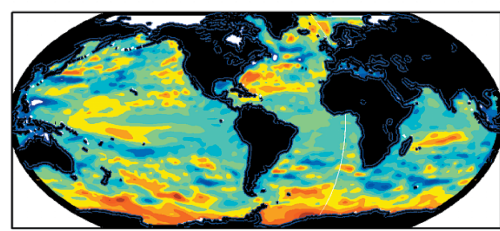

$-0.1$

0.1

Plate 7. Annual mean seasurface elevation anomaly (meters) relative to a 14-year mean (see Wunsch and Heimbach, 2006) in meters. Alternate years are shown for clarity. Note that a $1-\mathrm{cm}$ elevation change in $4000 \mathrm{~m}$ of water corresponds to a volume transport of about 7Sv at mid-latitudes. Thus these results depict a very large, complex interannual variability that probably has significant long-term consequences. 
ranging from days and weeks to thousands of years (e.g., Manabe and Stouffer, 1994; Schmittner et al., 2003). But as with any complex piece of equipment, whether made of metal or numerical code, one must test and calibrate the machine before it can be usefully set running. (A vessel on autopilot with a slightly misaligned compass will, if run long enough, ultimately land one on the rocks, even though the system may be adequate for short times - a simple example of the perils of time-integrating models.)

Calculations with ever-more complicated numerical models, but less-well-informed users, have attracted worried notice in a variety of fields (e.g., May, 2004; Post and Votta, 2005). For example, May (2004) has this to say about biological models:

... the increasing speed and sophistication and ease of use of computers enables an increasingly large number of life scientists who have no substantial background in mathematics to explore 'mathematical models' and draw conclusions about them. Such activity usually consists of representing sensible and evidencebased assumptions as the starting point for a complicated and usually nonlinear dynamical system, assigning particular parameters (often in an arbitrary way), and then letting this complicated system rip. This represents a revolutionary change in such theoretical studies. Until only a decade or two ago, anyone pursuing this kind of activity had to have a solid grounding in mathematics. And that meant that such studies were done by people who had some idea, at an intuitive level, of how the original assumptions related to the emerging graphical display or other conclusions on their computer. Removing this link means that we arguably are seeing an increasingly large body of work in which sweeping conclusions.... are drawn from the alleged working of a mathematical model, without clear understanding of what is actually going on. I think this can be worrying.

and,

Sadly, examples of the application of statistical 'confidence intervals' to distributions resulting from making arbitrary assumptions about essentially unknown parameters, and then endowing this with reality by passage through a computer, continue to proliferate.

Simply substituting "ocean circulation" or "climate" for "life sciences" conveys the appropriate message. How does one test (calibrate) ocean models? What is their predictive horizon for different variables (assuredly not the same for all)? Can one infer the behavior of such fluids from onedimensional simplifications such as conveyor belts? What is the atmospheric response? Atmosphere and ocean are fluid and global; one cannot a priori assume that some region or physics can be omitted as inconsequential, particularly as integration time scales are extended.

It is often argued that because of the comparative paucity of data, much simplified models can be used to describe and understand the ocean of the past. Unhappily, the inference is fallacious - requisite model complexity is dictated not by the amount of data, but by the physics and kinematics (and also the biology and chemistry where relevant) believed to govern the system. Consider a modern analogue: Suppose there exists a single annual average temperature at some position in the ocean $\bar{\theta}\left(\phi_{1}, \lambda_{1}, z_{1}\right) \pm \Delta \theta$ (where the $\pm \Delta \theta$ is meant as a reminder that observations always have an associated error). A GCM is run with (say) $1^{\circ}$ horizontal resolution driven by the best available forcing boundary conditions, and the model annual average temperature is computed at the same location, $\bar{\theta}_{m}\left(\phi_{1}, \lambda_{1}, z_{1}\right)$. Suppose further that $\left|\bar{\theta}_{m}\left(\phi_{1}, \lambda_{1}, z_{1}\right)-\bar{\theta}_{m}\left(\phi_{1}, \lambda_{1}, z_{1}\right)\right| \gg \Delta \theta$, that is, the model gets it demonstrably wrong. Although there are many reasons why a model can miscalculate a temperature, one plausible reason is that $1^{\circ}$ horizontal resolution is simply too coarse to govern the physics of temperature at the particular location. In many cases therefore, one could readily justify the inference that a much more complex model was required to reproduce even a single data point. Of course, if $\Delta \theta$ is arbitrarily large, then any model passes the test.

Box models (the Stommel, 1961, two-box model is the outstanding example) are often used to represent either the ocean alone or the oceanic component of coupled systems. Such models are extremely useful in capturing and analyzing particular physical mechanisms, in the sense of what is commonly called "geophysical fluid dynamics." They can be thought of as helpful extensions of the scale analyses fluid dynamicists do to obtain order of magnitude estimates of possible equation balances. Trouble sets in only when results of such grossly oversimplified systems and analyses are asserted to be realistic and to dominate the real world. To the extent that a two-box model e.g., is producing realistic oceanic heat or mass fluxes, when it is otherwise believed that a turbulent eddy resolving fluid is being described, an extremely important and difficult "turbulence closure" problem has been solved. One has succeeded in producing a predictive capability in a turbulent fluid by use of much reduced equations - the goal of generations of fluid dynamicists. Whether such claims would withstand close scrutiny is doubtful.

More generally (e.g., Wunsch, 2004), there is no understanding of the degree to which a one- or two-physical dimensions fluid system can represent the three-dimensional one. The behavior of systems in three-dimensions is generally drastically different from that in two (e.g., Esslinger and Blatter, 2006, for a much simpler condensed-matter physics example). Even for a three-physical dimensional model, coarse resolution represents a drastic dimension reduction in phase space. Carefully tuned simplified models can describe important elements of complex systems for short times. But does a simplified oceanic or coupled model run for 1000 
years really have skill in all the elements of concern? Almost nothing seems to be known of the answer to this question, and the burden of proof would appear to be on the claimant, given the inference of production of a successful turbulence closure and small accumulated errors. (Dijkstra, 2005, is an interesting summary of the subject, but the result is inconclusive.)

All numerical models have errors from a wide variety of sources, including truncated physics (chemistry, biology), numerical representation of continuous fields, initial condition and boundary condition errors, erroneous sub-grid scale parameterizations, and coding mistakes. Little is known quantitatively about the magnitudes and effects of these errors on the solutions, except that the errors never vanish, and will have a tendency to accumulate. Accumulation with time of error in models is important because model "climate" can become just the summed errors. Attempts to understand the nature of such errors are rare. (Examples include Hecht et al., 1998, who examine the effects of numerical schemes; Griffa et al., 2004, discussing errors in Lagrangian trajectories; and Large and Danabasoglu, 2006, discussing the bias errors occurring in coupled ocean-atmosphere models. No study known to me attempts to quantify climate or ocean model extrapolation errors.)

Two types of errors must be contemplated: random and systematic. Consider, for example, a $1 \mathrm{~mm} / \mathrm{s}$ systematic error in the computation by a model of the Lagrangian velocity at a point. At the end of 100 years of integration, a parcel of fluid will have a position error of $3000 \mathrm{~km}$. In that model, a carbon-rich parcel of fluid may well be in the wrong model ocean, if such errors are present (are they?). An equivalent problem exists for vertical velocities, in which comparatively minute systematic errors can take water parcels that belong in the abyss, all the way to the seasurface, and vice-versa.

Random errors are much more familiar and easier to analyze. Many scientists appear to believe that random errors will "average-out" in models run over long enough times. But that comforting sense runs counter to the behavior of random walks in which in a process whose true mean value is zero, the system can accumulate very large divergences from that mean (the drunkard's walk is the classical example). It is easy to generate examples (e.g., Hasselmann, 1976; Wunsch, 2001) in which a system can drift far from its true average state even when driven by the simplest of zero-mean random fluctuations. Thus in the ship's autopilot analogy, a random steering error, with zero mean, will with probability nearing unity, miss the assigned position by an amount growing with the length of the voyage. Errors are usually bounded in some way, but often trivially so- the ship's position error never exceeds one-half the circumference of the earth, as a stopped clock never has an error larger than 12 hours. Model bounds are similarly often uninteresting, whether due to such kine- matic constraints or to some sophisticated feedback or saturation effects. Skill measures must account for trivial bounding effects.

It is sometimes argued (A. Schmittner, personal communication, 2007) that the ability of an oceanic GCM to mimic large-scale tracer distributions during some time interval, be it the past, present or future, must be interpreted as implying the models are skillful. That ability can be taken as a necessary, but very insufficient condition for skill. Large-scale tracer distributions are very weak constraints on models (see Wunsch, 1988) and evidently modern oceanography shows that both the small-scale flows as observed, or assumed largescale laminar flows, can readily produce large-scale variations in tracers. As a consequence, the inverse problem of moving from tracer distributions to flow fields is grossly underdetermined (which is just another way of saying that meeting the requirement of mimicking an observed distribution is a very weak one). Even the far more constrained oceanic density field can be rendered in a visually nearly indistinguishable way by two very different theories of the thermocline (e.g., Pedlosky, 1996; Vallis, 2006) - one diffusive, the other a near-perfect fluid. Reproduction of scalar fields on the large scale, an integral over space and time, is a weak test of a model and no guarantee of predictive ability.

Some feeling for the problem can be obtained e.g., from Sun and Bleck (2006) who compared the circulations in four modern coupled GCMs of much more than "intermediate complexity." They studied both control and doubled $\mathrm{CO}_{2}$ scenarios. Means and variability in the overturning in controls and doubled $\mathrm{CO}_{2}$ stories are remarkably different between the models, and the duration of the computations is only 200 years. Sun and Bleck (2006) were unable to fully explain the differences nor to decide whether any one of the models was better than the others, nor whether the slowdown of the meridional overturning was primarily due to heating or freshwater injection or both or to circulation shifts affecting convection. Results such as these raise the question as to which model computations of mean meridional overturning, its variability, and related heat and salt transports would be regarded as reliable when the time spans extend to the Last Glacial Maximum and beyond.

S. Sun (private communication, 2006) has computed the meridional oceanic heat transport for the last 10 years of the control and $\mathrm{CO}_{2}$ doubling calculations, with the results shown in Plate 8. What are the consequences to a model climate calculation if e.g., the oceanic meridional transport of heat at mid-latitudes is too small by $10 \%$ ? If the true value is $1 \mathrm{PW}$, then after 100 years, the model has misplaced $3 \times 10^{23} \mathrm{~J}$. This misplacement may be of no climate consequence, but that conclusion would need to be justified (e.g., it could melt, or make, a significant amount of ice: the heat of fusion for ice is about $3.3 \times 10^{5} \mathrm{~J} / \mathrm{kg}$ ). 
GISS EH: Control (solid), $2 \times \mathrm{CO}_{2}$ (dashed)

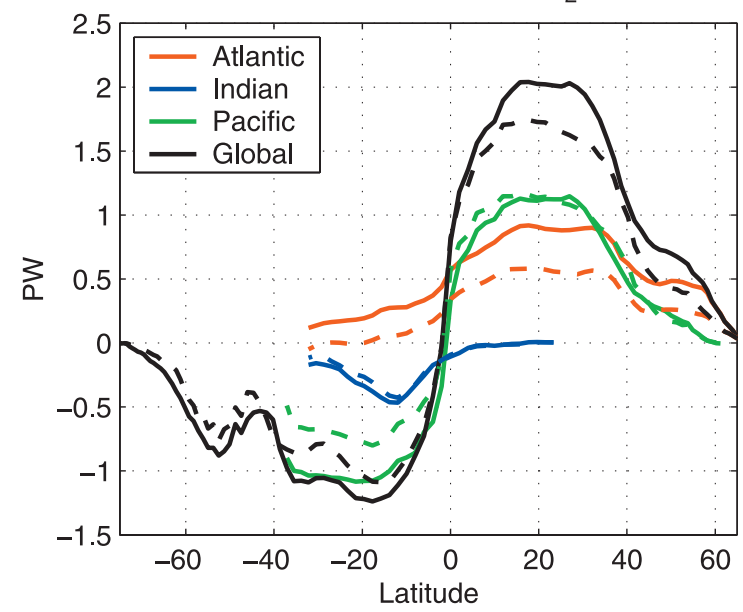

GFDL: Control (solid), $2 \times \mathrm{CO}_{2}$ (dashed)

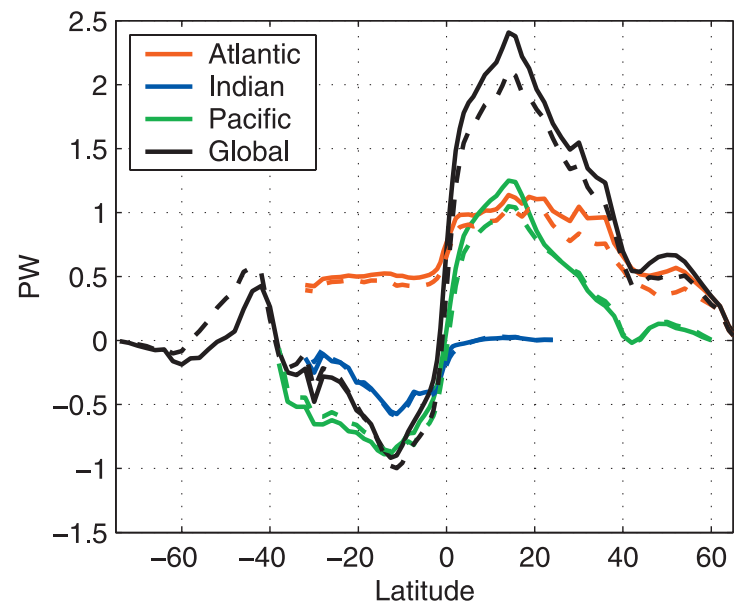

GISS ER: Control (solid), $2 \times \mathrm{CO}_{2}$ (dashed)

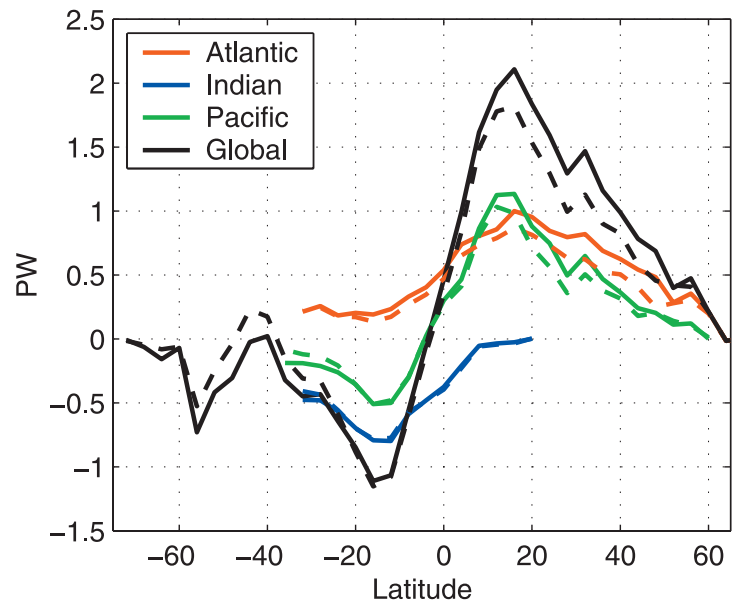

NCAR: Control (solid), $2 \times \mathrm{CO}_{2}$ (dashed)

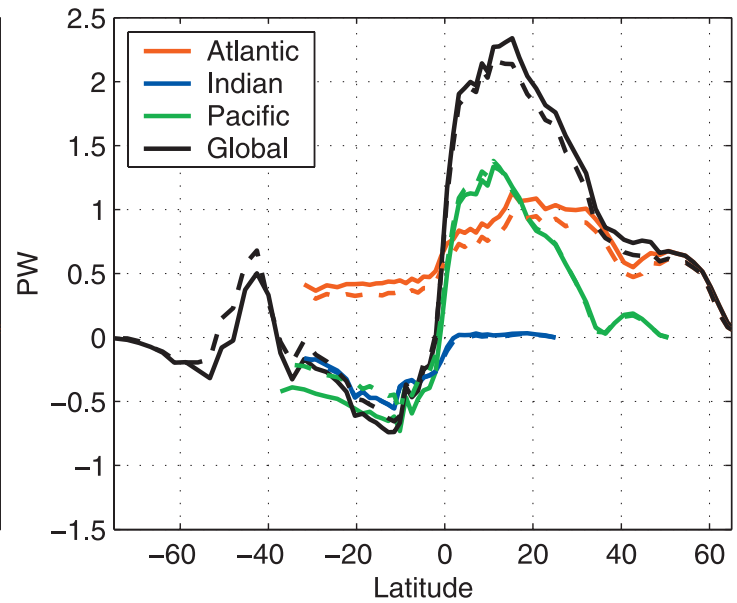

Northward heatflux 10-yr mean at yr 200

Plate 8. Meridional heat transport over the terminal 10 years for four climate models in control and doubled $\mathrm{CO}_{2}$ configurations. Note the striking differences between the control runs in the southern hemisphere, extending to sign changes, and comparatively modest changes between controls and doubled $\mathrm{CO}_{2}$. (From S. Sun, personal communication, 2006.) GISS, Goddard Institute for Space Studies (NASA; two different models); NCAR, National Center for Atmospheric Research; GFDL, Geophysical Fluid Dynamics Laboratory (NOAA). Feedbacks and bounds of various sorts will prevent indefinite accumulation of heat transport errors, but nevertheless are expected to grow with increasing integration times. 
Yet another version of the same problem is shown in Figure 4, for Arctic ice cover in 16 climate models used in the forthcoming (at this writing) Intergovernmental Panel on Climate Change (IPCC), fourth assessment report (AR4) studies. After only 100 years, the models differ greatly in their predicted sea ice cover, even though (Eisenman et al., 2007) the quality of fit to the present-day data in all the models is approximately the same. Sea ice cover can have profound influence on climate, and divergences such as seen in the figure raise questions about model skills when run out for thousands of years (and see Weber et al., 2007).

Any omitted physics or chemistry or biology represents a potential source of bias in long model runs. Ocean or coupled models improperly representing sea ice formation and properties, or using surface water runoffs that are incorrect, or miscomputing mixed layer properties, or a myriad of other possibilities, are systematically misrepresenting processes that can over long periods grow into significant errors. If one integrates long enough, almost any small systematic error can grow to dominate regional or global model climate properties_-rendering climate modelling uniquely challenging. One must bound an enormous range of physical and chemical processes that of necessity are omitted from the models.
Obtaining model errors has to be done a priori, because modern and paleodata have commonly been used to "tune" the models and thus render true testing very difficult. An "a priori" error analysis would consider, e.g. truncation and rounding errors from the numerical scheme; the effects of initial condition errors; approximated physics; parameterizations; etc. Model intercomparisons, ensemble calculations, etc. provide useful lower bounds. It's a long chore, but a necessary one.

\subsection{Heat and Water Transport Problems}

As already noticed, the interaction between the ocean and the atmosphere is only indirectly dependent upon the oceanic mass transport distribution and rates. The direct interaction is through the transfer of enthalpy, fresh water, and carbon, and even major oceanic mass transport changes leaving the airsea heat and fresh water exchanges unmodified would have no immediate climate consequences. Because the mean global temperature is determined by the balance of net incoming solar radiation in the tropics and its re-radiation to space at higher latitudes, much of the climate system is defined by the way in which the ocean and atmosphere

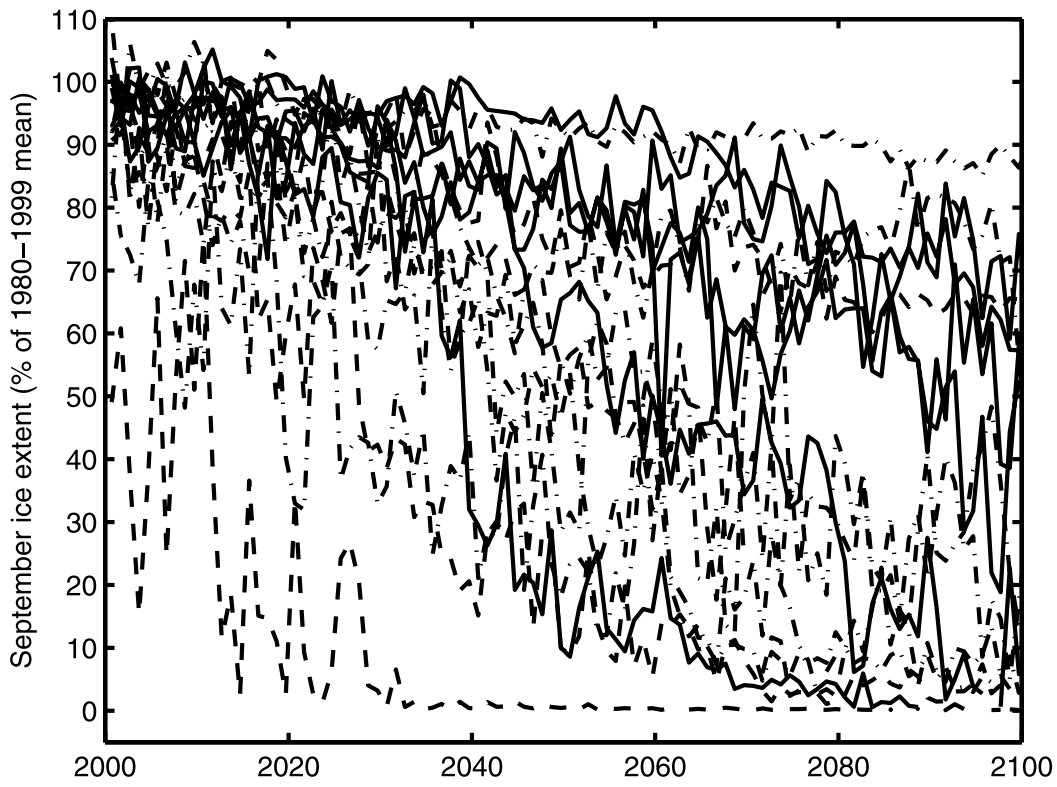

Figure 4. Arctic ice cover (September) in percentage in 16 models used in the forthcoming IPCC AR4 report, as analysed by Eisenman et al. (2007; compare to Zhang and Walsh, 2006). Initial coverage varies between the models, and the degree of change varies between almost nothing and 100\% (I. Eisenman, J. Wettlauefer, private communication, 2007). Note that the duration of the computation is only 100 years, that the divergence of the models is necessarily bounded both above and below, and that the authors could not distinguish the models by the quality of their fit to existing data. To the extent that sea ice affects the climate system, such results suggest strong divergence among the models as time evolves. 
together carry warm air/fluid from the tropics towards the poles with a consequent heat flux partitioning between them. Figure 5, adapted from Wunsch (2004), is one estimate of the zonally integrated time-mean flux of heat in the ocean and atmosphere. The total curve shown in the figure is the true "global conveyor" as it reflects the combined contributions of ocean and atmosphere, which in concert must maintain global heat balance.

As discussed in Wunsch (2005), some of the salient features of this estimate are the strong hemispheric asymmetry of the oceanic contribution, but the near anti-symmetry of the total transport, and the general lack of understanding of what really determines the shapes and magnitudes of these curves (see Stone, 1978; 2007). Without understanding the answers to these questions for the modern system, it is very difficult to predict how they would change under boundary conditions differing from those of today (e.g., in the presence of continental ice sheets, or shifted continents, or much changed $\mathrm{CO}_{2}$ ).

Verbal "conveyor-belt" arguments that a weakening of the North Atlantic mass transport ("shutdown of the Gulf Stream" in some of the more excited accounts) must lead to a colder atmosphere over Europe or a Younger Dryas episode are almost impossible to evaluate given Figure 5. The total high latitude contribution of the ocean to the combined transport is small and any inference that the atmosphere must cool would be the end result of a very complex air/sea interaction, with the requirement that the total Earth heat budget should remain in very close balance.

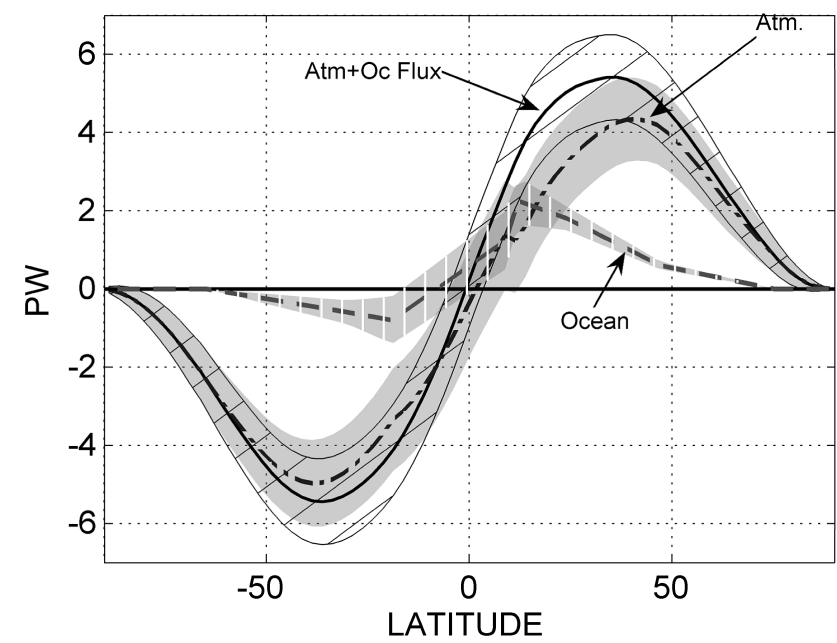

Figure 5. Estimates, with error bars, of the combined meridional transport of heat by the atmosphere and ocean (thick solid curve) and estimates of the separate contributions (adapted from Wunsch, 2005). Note the near-anti-symmetry of the combined results, the striking asymmetry of the oceanic component, and the small highlatitude contribution by the oceans.
The discussion of the fresh water transports would be similar, although it has been less highly developed (atmospheric fresh water transport paths are very complex and time-varying; see e.g. Newell and Zhu, 1994), the air/sea transfer of moisture does not depend upon any single parameter as simple as the local air/sea temperature difference and while the ocean transports salt and the atmosphere does not, both transport fresh water. (Some of the atmospheric heat transport in Figure 5 owing to latent heat flux can equally well be attributed to the ocean; see e.g., Bryden and Imawaki, 2001).

\subsection{The Mixing Problem}

Property mixing is one of the most complex and important of all oceanographic problems, because its quantification and representation depend explicitly upon the exact nature of the turbulence closure used to straddle the space scales between model resolution and the molecular one where structure dissipation ultimately occurs. A large literature about the modern ocean has accumulated (Kantha and Clayson, 2000; Griffies, 2004; Thorpe, 2005). In the earliest and probably still most common representation, turbulent mixing was supposed, by analogy, to be mathematically identical to the known molecular form, e.g. for temperature in the ordinary advection diffusion equation,

$$
\kappa \nabla^{2} \theta
$$

where $\nabla^{2}$ is the three-dimensional Laplacian operator, except that the coefficient $\kappa$ was replaced by much larger values, and by recognition that the oceanic stratification would render terms such as $\langle\mathbf{u} \cdot \nabla \theta\rangle$, if regarded as turbulent diffusion, very different in the vertical direction than in the horizontal, by replacing Eq. (4) by the Fickian form,

$$
\frac{\partial}{\partial z}\left(K_{V} \frac{\partial\langle\theta\rangle}{\partial z}\right)+\nabla_{2}\left(K_{H} \nabla_{2}\langle\theta\rangle\right),
$$

where $K_{V}, K_{H}$ are empirical eddy coefficients often constant, $\nabla_{2}$ is the two-dimensional gradient, and the bracket implies some space/time low-pass filtered fields are being represented. These, and much more sophisticated turbulent closure forms, have been employed in ocean theory and modelling for decades, and although their use has made most practitioners somewhat uneasy, it is only recently that clearly deleterious consequences of their employment have become clear.

One might have hoped, for example, that bulk oceanic transport properties such as that for heat, would be largely independent of the particular values of $K_{V}, K_{H}$ much as the 
volume transport of the Ekman layer, which is based upon an analogous turbulence closure for momentum diffusion, produces net volume transports independent of the empirical coefficients. Unhappily (Bryan 1987; Dalan et al., 2005; etc.) it has been shown repeatedly that such properties as heat transport, and water mass distributions tend to depend directly upon the values chosen.

Even more interesting and troubling for theoreticians and modelers, it has become unmistakable in recent years that oceanic mixing is extremely non-uniform not only in the vertical dimension, but also in the horizontal. Although already suggested as a possibility by Munk (1966), most striking was the discovery (Polzin et al., 1997; Heywood et al., 2002) that quantities such as $K_{V}$ change by two orders of magnitude in the presence of abyssal topography. Only now (Marotzke, 1997; Simmons et al., 2004; Saenko, 2006, and several others) are models tentatively beginning to remove the major qualitative shortcomings of uniform mixing representations. When one considers the energy sources for the turbulence controlling the mixing (e.g., Wunsch and Ferrari, 2004), the dependence upon wind and tides suggests possibly strong temporal variations as the climate and sea level vary.

For climate purposes, the consequences of both spatial and temporal variability are immediate and not hard to understand. In a stably stratified ocean, like the one we observe, there is an approximate balance in the abyss of the vertical advection of $C$ against diffusion of the same property. The most widely used of such balances is that of Munk (1966) which is,

$$
w \frac{\partial \rho}{\partial z}=\frac{\partial}{\partial z}\left(\kappa(z) \frac{\partial \rho}{\partial z}\right)
$$

where $\kappa(z)$ is a vertical turbulent mixing coefficient and $w$ is the vertical velocity. With $\kappa(z)=0, w=0$. But geostrophic balance, leading to Eq. (1), and mass conservation also implies,

$$
v \approx \frac{a \sin \phi}{\cos \phi} \frac{\partial w}{\partial z}
$$

If there is no local vertical mixing and the fluid is vertically stratified, there cannot be any $w$, hence no meridional flow, nor advective transport of heat, nor anything else. The largescale consequences of such constraints for the oceanic circulation and climate are quite profound. Plate 4 suggests the great difficulty that the ocean has in moving material properties in the meridional direction. The behavior of meridional transports and overturning circulations as functions of spatially and temporally varying mixing rates is only now being explored. Whether a model that does not properly represent this physics has any predictive or descriptive skill over millennia is unknown. (The Munk balance is explicitly restricted to the abyss - in regions of surface outcrops of isopycnals, as in the upper layers of the Southern Ocean-Eq. (5) would be inapplicable.)

Everyone uses models - it is the only way to do science. Some of those models are numerical, but many are analytical, or conceptual. Grossly over-simplified models are powerful ways of obtaining understanding (it is the basis of the subject known as geophysical fluid dynamics). Problems arise in climate studies when such models are used to claim that the particular process being analyzed is the dominant one, or that a model capable of being tuned to some set of observations can, without much further justification, be used to calculate expected behavior far in the past or future. As already noted, coarse resolution models represent an important reduction in model complexity. To the extent that they are capable of skillful computations over long periods of time, one has achieved, remarkably, the ability to quantitatively parameterize smaller, unresolved, scales - a goal of fluid dynamics for two hundred years, and one which, generally has gone unfulfilled (except perhaps in the climate context [?]).

As a practical matter, much of the modeling community seems largely to have leaped from very simple box models to the use of global coupled climate ones seeking realism. Along the way, the conventional geophysical fluid dynamics stage of analyzing true "intermediate complexity" models involving water-covered planets, or those with terrain freehemispheric continents, or simplified geometries, flat-bottomed oceans, controlled albedos, etc., that would lead one to answering seemingly fundamental puzzles such as the way the ocean and atmosphere partition their heat transports (Stone, 1978, 2007; Wunsch, 2005) was skipped. Perhaps the time has come to take a step backward toward finding the basic geophysical fluid dynamics principles controlling climate.

\section{SPECIFIC PALEOCEANOGRAPHIC CONCERNS}

The contemporary picture of the general circulation of the ocean is one of (1) intense turbulent flows and interactions, with temporal fluctuations on all measured time and space scales, but nonetheless displaying (2) large-scale, contourable scalar properties such as temperature, oxygen, salinity, carbon, and nutrients. The compelling, but nonetheless erroneous, inference that large-scale quasi-steady scalar distributions implied large-scale quasi-steady flow fields, is one of the most serious problems for understanding the paleocirculation rates.

With some minor exceptions, all data available to the paleoceanographer concerning the past ocean climate state are 
scalar properties recorded in deep-sea cores, such as $\delta^{18} \mathrm{O}$, $\delta^{13} \mathrm{C}$, hematite stained grains, etc. Data sets are interpreted as proxies for a variety of oceanographically interesting parameters such as nutrients, temperature, or salinity. Setting aside all of the important and difficult questions about the accuracy of the relations of proxy to physical variable of interest, suppose that global, three-dimensional, accurate estimates of the paleoceanographic temperature, salinity, oxygen and nutrient fields were magically available from cores at some time, $T$, when the ocean was thought to be in quasi-equilibrium. (A data set like this, of course, exceeds that available for the contemporary ocean, but with the WOCE hydrography [see e.g., Siedler et al., 2001; http://www.woce.org/atlas_webpage/] we are about as close to it as we are likely to be anytime soon.)

The problem as just stated was that faced by oceanographers such as G. Wüst and others, who attempted to find ways to convert information about water mass properties and volumes into inferences about how rapidly the fluid was moving. We now know that they had to fail, as there is no relationship between water mass volumes and rates of production or removal. Were such a relationship available, it would revolutionize general circulation physical oceanography. Most of what is known about rates of fluid movement is obtained from the thermal wind of the dynamic method combined with the constraints of direct measurement or through the conservation rules (for salt, mass, ...) used in inverse calculations.

Of course, with the hypothetical paleodata set assumed, inverse methods could be used. Paleo density could be computed from paleo temperatures and salinities, the thermal wind determined, and the various (near) conservation rules for e.g., salt or oxygen at depth used to compute the missing reference level velocities (integration constants), $b$ of Eq. (1), as well as higher order elements not discussed here. Without those extra constraints, one is forced to arbitrary level-of-nomotion or related methods as done e.g., by Lund et al. (2006), in which mass flux was inferred from estimated geostrophic shear alone-and if that were possible, the level-of-nomotion problem would have been solved over 100 years ago.

Thus the paleo circulation problem largely reduces to finding ways to determine the rates of movement of water from scalars. There are several possible approaches: (1) Paleo densities and the thermal wind combined with conservation statements for mass or other properties can be used with inverse methods to determine reference levels. A recent attempt at understanding this problem is described by Gebbie and Huybers (2006). (2) Advection/diffusion equations for tracers with known rates of decay $\left({ }^{14} \mathrm{C}\right.$, for example) or production (e.g., protactinium) will constrain the flow field. Such rate data can also be used within the inverse model framework; Huybers et al. (2007) is an example. (3) The data in methods (1) or (2) can be combined through state estimation methods (e.g., Wunsch, 2006c) to force a general circulation model to consistency with the data. This latter approach is the most general one for the use of any type of in situ observations.

In principle, subject to the error issues described above, GCMs can be used to calculate the general circulation-if driven by realistic boundary conditions. With ocean-alone models, the requirements involve both realistic initial conditions, perhaps from the paleo density estimates, as well as wind-forcing and air-sea buoyancy exchanges (enthalpy and freshwater). The wind problem is the leading one-both because the energy supply for the circulation comes primarily from the wind, but also because the well-established theories show that the oceanic response to changes in wind strength and patterns is immediate, both large and small scale, and signals penetrate to the abyss almost instantaneously.

Apart from the equatorial band, the circulation is most sensitive to the curl of the wind stress, that is, to its derivatives, not the wind itself, rendering the system even more sensitive to small changes. Claims to have computed circulations over centuries to millennia without any understanding of the accuracy of the wind used, whether imposed through a coupled atmospheric model or (hypothetically) through evidence of paleo winds must be regarded as mere scenarios rather than quantitatively useful results (cf. Wunsch, 2006b). Because the atmospheric component of climate depends most directly upon its exchanges of enthalpy and freshwater with the ocean, those exchanges must be modelled accurately-otherwise the wind patterns, and then the exchanges themselves will be erroneously modified. Accumulating errors will then limit the time horizon of utility of the calculation.

\section{CONCLUDING REMARKS}

The existence of complex three-dimensional time-varying pathways is an essential part of a description of the ocean circulation, with the complexity per se even more important than its details. Study of the paleo (and future) ocean circulation involves extrapolation of models over large ranges of time, and comparison with thin and sometimes controversial proxy data. Models that are oversimplified compared to the present system (the euphemism is "intermediate complexity") may well be adequate for calculating cause and effects over time spans from decades to thousands of years, but clear demonstration of that skill is necessary. Anyone can write a model: the challenge is to demonstrate its accuracy and precision in an extrapolation mode. Otherwise, the scientific debate is controlled by the most articulate, colorful, or adamant players. 
Some of the reviewers of this paper are very unhappy with its import - that one must be very careful in separating sometimes plausible rationalizations of the ocean circulation and climate system from equally plausible alternative descriptions. To an extent, the messenger is being attacked because of the message. But the route to solving a difficult problem begins with its recognition and definition. When oversimplified conclusions are translated into truths (the textbook employment of the global conveyor ribbon is the outstanding example), a field can be distorted for decades until the flimsy foundation is finally recognized. Careful delineation of reasonable assumptions (as in the oceanographers' use of levelsof-no-motion) as distinct from demonstrable facts, with simultaneously exploration of alternative interpretations is required, so that a distorted physical picture is not rendered as "truth" (as happened with levels-of-no-motion). Models are extremely important and enlightening, but much better understanding of their real simulation and predictive skills is necessary.

Acknowledgments. Supported through the National Ocean Partnership Program (NOPP) by NASA and NOAA as part of the ECCO-GODAE Consortium. This paper is a reworking of an oral presentation made at the SCOR/IMAGES Working Group on Paleocean Circulation Workshop 20-23 March 2005 at Georgia Institute of Technology. P. Huybers, G. Gebbie, and O. Marchal provided some very helpful comments. Thanks to S. Sun for the model heat transport computations.

\section{REFERENCES}

Bard, E., B. Hamelin, M. Arnold, L. Montaggioni, G. Cabiouch, G. Faure, and F. Rougerie, Deglacial sea-level record from Tahiti corals and the timing of global meltwater discharge, Nature, 382, 241-244, 1996.

Bradley, R.S., Paleoclimatology, 2nd Ed., 610 pp., Academic, San Diego, 1999.

Brewer, P.G., C. Goyet and D. Dyrssen, Carbon dioxide transport by ocean currents at $25^{\circ} \mathrm{N}$ latitude in the Atlantic Ocean, Science, 246, 477-479, 1989.

Bryan, F., Parameter sensitivity of primitive equation ocean general circulation models, J. Phys. Oc., 17, 970-985, 1987.

Bryden, H.L., and S. Imawaki, Ocean heat transport, in, Ocean Circulation and Climate, 455-474, G. Siedler, J. Church and J. Gould, eds., Academic, San Diego, 2001

Dalan, F., P.H. Stone, and I.V. Kamenkovich, Sensitivity of the ocean's climate to diapycnal diffusivity in an EMIC. Part I: equilibrium state, $J$. Clim., 18, 2460-2481, 2005.

Defant, A., Physical Oceanography, Vol. 1, 598 pp, Pergamon, N.Y., 1961.

Dijkstra, H.A., Nonlinear Physical Oceanography, 2nd Ed., 532 pp., Springer, Dordrecht, 2005.

Eisenman, I., N.Untersteiner, and J. S. Wettlaufer, On the reliability of simulated Arctic sea ice in global climate models, Geophys. Res. Letts., submitted, 2007.

Esslinger, T. and G. Blatter, Atomic gas in flatland, Nature, 441, 1053-1054, 2006

Fratantoni, D.M., North Atlantic surface circulation during the 1990's observed with satellite-tracked drifters, J. Geophys. Res., 106, 22,067-22,093, 2001.

Ganachaud, A., and C. Wunsch, Oceanic nutrient and oxygen fluxes during the World Ocean Circulation Experiment and bounds on export produc- tion, Global Biogeochem. Cycles, 16(4), 1057, DOI:10.1029/ 2000GB001333, 2002.

Ganachaud, A., Large Scale Oceanic Circulation and Fluxes of Freshwater, Heat, Nutrients and Oxygen, PhD Thesis, MIT/WHOI, 266pp., 1999

Gebbie, G., and P. Huybers, Meridional circulation during the Last Glacia Maximum explored through a combination of South Atlantic $\delta^{18} \mathrm{O}$ observations and a geostrophic inverse model, Geochem. Geophys. Geosyst., 7 , Q11N07, doi:10.1029/2006GC001383, 2006.

Griffa, A., L.I. Piterbarg, T. Ozgokmen, Predictability of Lagrangian particle trajectories: Effects of smoothing of the underlying Eulerian flow, J. Mar. Res., 62, 1-35, 2004.

Griffies, S.M., Fundamentals of Ocean Climate Models, 518 pp., Princeton U. Press, 2004.

Hasselmann, K., Stochastic climate models. Part 1. Theory, Tellus, 28 473-485, 1976.

Hecht, M.W., F.O. Bryan and W. R. Holland, A consideration of tracer advection schemes in a primitive equation ocean model, J. Geophys. Res., 103 , 3301-3322, 1998

Heywood, K,J., A.C. Naveira Garabato, and D.P. Stevens, High mixing rates in the abyssal Southern Ocean, Nature, 415, 1011-1014, 2002.

Hogg, N.G., and W.B. Owens, Direct measurement of the deep circulation within the Brazil Basin, Deep-Sea Res. II-Topical Studies in Oceanog., 46, 335-353, 1999

Huang, R.X., Mixing and energetics of the oceanic thermohaline circulation, J. Phys. Oc., 29, 727-746, 1999.

Huybers, P., G. Gebbie, and O. Marchal, Can paleoceanographic tracers constrain meridional circulation rates?, J. Phys. Oc., 37, 394-407, 2006.

Joyce, T.M., A. Hernandez-Guerra, and, W.M. Smethie, Zonal circulation in the NW Atlantic and Caribbean from a meridional World Ocean Circulation Experiment hydrographic section at 66 degrees W, J. Geophys. Res., 106, 22095-22113, 2001.

Kantha, L.H., and C.A. Clayson, Small Scale Processes in Geophysical Fluid Flows, 888pp, Academic, San Diego, 2000.

Large, W.G., and G. Danabasoglu, Attribution and impacts of upper-ocean biases in CCSM3, J. Clim., 19, 2325-2346, 2006.

Lund, D.C., J.-L. Stieglitz, and W.B. Curry, Gulf Stream density structure and transport during the past millennium, Nature, 444, 601-604, 2006

Macdonald, A., and C. Wunsch, The global ocean circulation and heat flux, Nature, 382, 436-439, 1996.

Manabe, S., and R.J. Stouffer, Multiple century response of a coupled oceanatmosphere model to an increase of atmospheric carbon dioxide, J. Clim. 7, 5-23, 1994.

Marotzke, J., Boundary mixing and the dynamics of three-dimensional thermohaline circulation, J. Phys. Oc., 27, 1713-1728, 1997.

Martel, F., and C. Wunsch, The North Atlantic circulation in the early 1980's - an estimate from inversion of a finite difference model, J. Phys. Oc., 23, 898-924, 1993.

May, R., Uses and abuses of mathematics in biology, Science, 303 (5659), 790-793, 2004.

McIntyre, M.E., On global-scale atmospheric circulations, in, Perspectives in Fluid Dynamics, 557-624, G. K. Batchelor, H. K. Moffatt and M. G Worster, Eds., Cambridge Un. Press, Cambridge, 2000.

McManus, J.F., R. Francois, J.-M. Gherardi, L.D. Keigwin and S. BrownLeger, Collapse and rapid resumption of Atlantic meridional circulation linked to deglacial climate changes, Nature, 428, 834-837, 2004.

Munk, W., On the wind-driven ocean circulation, J. of Meteor., 7, 79-93, 1950

Munk, W.H., Abyssal recipes, Deep-Sea Res., 13, 707-730, 1966.

Newell, R.E. and Y. Zhu, Tropospheric rivers: a one-year record and a possible application to ice core data, Geophys. Res. Letts., 21, 113-116, 1994

Nilsson, J.,G. Broström, G. Walin, The thermohaline circulation and vertical mixing: does weaker density stratification give stronger overturning? $J$. Phys. Oc., 33, 2781-2795, 2003.

Pedlosky, J., Ocean Circulation Theory, 450 pp, Springer-Verlag, Berlin, 1996

Polzin, K.L., J.M. Toole, J.R. Ledwell, and R.W. Schmitt, Spatial variability of turbulent mixing in the abyssal ocean, Science, 276, 93-96, 1997.

Post, D.E. and L.G. Votta, Computational science demands a new paradigm, Physics Today, 35-41, 2005. 


\section{PAST AND FUTURE OCEAN CIRCULATION}

Reid, J.L., On the mid-depth circulation of the world ocean, in, Evolution of Physical Oceanography. Scientific Surveys in Honor of Henry Stommel, 70-111, B.A. Warren and C. Wunsch eds., The MIT Press (available online at http://ocw.mit.edu/ans7870/textbooks/Wunsch/wunschtext.htm, or by search at http://web.mit.edu), 1981.

Robinson, A.R., Ed., Eddies in Marine Science, 609 pp, Springer-Verlag, Berlin, 1983.

Saenko, O.A., The effect of a localized mixing on the ocean circulation and time-dependent climate change, J. Phys. Oc., 36, 140-160, 2006.

Schmittner, A., O.A. Saenko, and A.J. Weaver, Coupling of the hemisphere in observations and simulations of global climate change, Quat. Sci. Revs., 22, 659-671, 2003.

Siedler, G., J. Church, and J. Gould, eds., Ocean Circulation and Climate: Observing and Modeling the Global Ocean, 715pp, Academic, San Diego, 2001.

Simmons, H.L., S.R. Jayne, L.C. St. Laurent, and, A.J. Weaver, Tidally driven mixing in a numerical model of the ocean circulation, Ocean Mod., 3-4, 245-263, 2004.

Stommel, H., The westward intensification of wind-driven ocean currents, Trans. Am. Geophys. Un., 29, 202-206, 1948.

Stommel, H., Thermohaline convection with two stable regimes of flow, Tellus, 13, 131-149, 1961.

Stone, P.H., Constraints on dynamical transports of energy on a spherical planet, Dyn. Atm. Oceans. 2, 123-139, 1978.

Stone, P.H., The atmospheric general circulation: some unresolved issues, Dyn. Atm. Oceans, in press, 2007.

Sun, S. and R. Bleck, Geographic distribution of the diapycnal component of thermohaline circulations in coupled climate models, Ocean Modelling, 15, 177-199, 2006.

Sverdrup, H.U., M. W. Johnson and R.H. Fleming, The Oceans, 1087 pp, Prentice-Hall, Englewood Cliffs, N. J., 1942.

Sverdrup, H.U., Wind-driven currents in a baroclinic ocean; with application to the equatorial currents of the eastern Pacific, Proc. Nat. Acad. Scis. U.S.A., 33, 318-326, 1947.

Talley, L.D., Hydrographic Atlas of the World Ocean Circulation Experiment (WOCE) Volume 2: Pacific Ocean, Eds. M. Sparrow, P. Chapman, and J. Gould), International WOCE Project Office, Southampton UK, http://.www-pord.ucsd.edu/whp_atlas/pacific_index.htm, 2007.

Thorpe, S.A., The Turbulent Ocean, 439pp., Cambridge Un. Press, 2005.

Vallis, G.K., Atmospheric and Oceanic Fluid Dynamics: Fundamentals of Large-scale Circulation, 745pp., Cambridge Un. Press, Cambridge, 2006.

Weber. S.L.S.S. Drijfhout, A. Abe-Ouchi, M. Crrucifix, M. Eby, A. Ganopolski, S. Murakami, B. Otto-Bliesner, and W.R. Peltier, The modern and glaical overturning circulation in the Atlantic ocean in PMIP coupled model simulations, Clim. Past, 3, 51-64, www.clim-past.net/ 3/51/2007, 2007.

Whitworth III, T., B.A. Warren, W.D. Nowlin, Jr., S.B. Rutz, R.D. Pillsbury, and, M.I. Moore, On the western-boundary current in the Southwest Pacific Basin. Prog. Oceanog., 43, 1-54, 1999.

Wunsch, C., and P. Heimbach, Decadal changes in the North Atlantic meridional overturning and heat flux, J. Phys. Oc., 36, 2012-2024, 2006.

Wunsch, C., Transient tracers as a problem in control theory, J. Geophys. Res., 93, 8099-8110, 1988.

Wunsch, C., The Ocean Circulation Inverse Problem, 437 pp., Cambridge University Press, Cambridge, 1996.

Wunsch, C., Global problems and global observations, in, Ocean Circulation and Climate: Observing and Modeling the Global Ocean, 47-58, G. Siedler, J. Church and J. Gould, Eds., Academic, 2001.

Wunsch, C., Ocean observations and the climate forecast problem, in Meteorology at the Millennium, 233-245, R. P. Pearce, Ed., Academic Press, London, 2002.

Wunsch, C., Thermohaline loops, Stommel box models and Sandström's theorem, Tellus, 57A, 1-16, 2004.

Wunsch, C., The total meridional heat flux and its oceanic and atmospheric partition, J. Clim., 18, 4374-4380, 2005.

Wunsch, C., Towards the World Ocean Circulation Experiment and a bit of aftermath, in Physical Oceanography: Developments Since 1950, 181-201, M. Jochum and R. Murtugudde, Eds., Springer, New York, 2006a.

Wunsch, C., Abrupt climate change: an alternative view, Quat. Res., 65, 191-203, 2006b.

Wunsch, C., Discrete Inverse and State Estimation Problems. With Geophysical Fluid Applications, 371pp., Cambridge Un. Press, Cambridge, 2006c.

Wunsch, C. and R. Ferrari, Vertical Mixing, Energy, and the General Circulation of the Oceans, Ann. Revs. Fl. Mech., 36, doi:10.1146/annurev.fluid.36.050802.122121, 2004.

Yu, E.-F., R. François and M.P. Bacon, Similar rates of modern and lastglacial ocean thermohaline circulation inferred from radiochemical data, Nature, 379, 689-694, 1996.

Zhang, X. and J.E. Walsh, Toward a seasonally ice-covered Arctic Ocean: Scenarios from the IPCC AR4 model simulations, J. Clim., 19, 1730-1747.

C. Wunsch, Department of Earth, Atmospheric and Planetary Science, Massachusetts Institute of Technology, Room 54-1524, Cambridge, Massachusetts 02139, USA. (cwunsch@mit.edu) 